\title{
Dilated cardiomyopathy in the era of precision medicine: latest concepts and developments
}

\author{
Nicoletta Orphanou ${ }^{1,2}$ (1) $\cdot$ Efstathios Papatheodorou ${ }^{1} \cdot$ Aris Anastasakis $^{1}$ \\ Accepted: 30 June 2021 / Published online: 14 July 2021 \\ (c) The Author(s), under exclusive licence to Springer Science+Business Media, LLC, part of Springer Nature 2021
}

\begin{abstract}
Dilated cardiomyopathy (DCM) is an umbrella term entailing a wide variety of genetic and non-genetic etiologies, leading to left ventricular systolic dysfunction and dilatation, not explained by abnormal loading conditions or coronary artery disease. The clinical presentation can vary from asymptomatic to heart failure symptoms or sudden cardiac death (SCD) even in previously asymptomatic individuals. In the last 2 decades, there has been striking progress in the understanding of the complex genetic basis of DCM, with the discovery of additional genes and genotype-phenotype correlation studies. Rigorous clinical work-up of DCM patients, meticulous family screening, and the implementation of advanced imaging techniques pave the way for a more efficient and earlier diagnosis as well as more precise indications for implantable cardioverter defibrillator implantation and prevention of SCD. In the era of precision medicine, genotype-directed therapies have started to emerge. In this review, we focus on updates of the genetic background of DCM, characteristic phenotypes caused by recently described pathogenic variants, specific indications for prevention of SCD in those individuals and genotype-directed treatments under development. Finally, the latest developments in distinguishing athletic heart syndrome from subclinical DCM are described.
\end{abstract}

Keywords Dilated cardiomyopathy · DCM - Cardiomyopathies · Precision medicine $\cdot$ Inherited cardiac diseases · ARVC LMNA · FLNC · BAG3 - TMEM43 · PLN · DSP · Athletic heart syndrome · Hypokinetic non-dilated cardiomyopathy ·

Molecular cardiology $\cdot$ Heart failure

\section{Introduction}

Dilated cardiomyopathy (DCM) is characterized by left ventricular (LV) systolic dysfunction and LV enlargement, in the absence of abnormal loading conditions such as hypertension, valvular disease, or coronary artery disease (CAD) that could explain the myocardial abnormality [1-3]. The presence of the disorder is defined by an LV end-diastolic diameter (LVEDD) greater than 2 standard deviations (SD) of the predicted values and LV fractional shortening $<25 \%$ or an LV ejection fraction (EF) $<45 \%$ [2]. Predicted values are calculated according to the formula of Henry, corrected for age and body surface area, and are expressed as a percentage of the predicted diameter as follows: Predicted

Nicoletta Orphanou

nicoletta.orphanou@gmail.com

1 Unit of Inherited and Rare Cardiovascular Diseases, Onassis Cardiac Surgery Center, Athens, Greece

2 Cardiology Department, Athens General Hospital "G. Gennimatas", Athens, Greece
LVEDD $=\left(45.3 \times\right.$ body surface area $\left.a^{0.3}\right)-(0.03 \times$ age $)-7.2$ [4]. A value of LVEDD $>112 \%(>2 \mathrm{SD})$ is a diagnostic criterion for DCM while a value $>117 \%(2 \mathrm{SD}+5 \%)$ increases specificity. Until recently, the management of DCM patients has involved traditional heart failure management approaches including drugs, devices, and heart transplantation when indicated. The prognosis of DCM patients has significantly improved over the last decades due to pharmacological and non-pharmacological advances, earlier diagnosis due to familial screening, and pre-participation cardiac evaluation and individualized long-term follow-up. In the past few decades the prognosis of DCM has significantly improved, and survival along with no need for heart transplantation has risen to $>80 \%$ at 8-year follow-up [5].

\section{Classification of cardiomyopathies}

Over the years there have been several attempts to classify cardiomyopathies. The American Heart Association (AHA) has adopted a different approach from the European Society 
of Cardiology (ESC). The AHA firstly differentiates primary cardiomyopathies (i.e., those predominantly affecting the heart) which are further subdivided to genetic, acquired, or mixed according to their etiology [6]. In 2007 the ESC proposed a classification of cardiomyopathies based on their phenotypic and morphological characteristics, further subdividing them to familial and non-familial (secondary) forms [1]. However, due to overlapping phenotypic expression and variable penetrance, cardiomyopathies often cannot be clearly assigned to a specific category $[1,3,6,7]$.

\section{Classification concepts of dilated cardiomyopathy}

Over the past few decades, the etiology and natural history of DCM have been further elucidated [1, 8-11]. It has been demonstrated that various etiologies, causing LV dysfunction may manifest with the same clinical phenotype as DCM [12-14]. According to the ESC classification of cardiomyopathies, DCM can be further subdivided into two main groups, genetic or acquired. There are, however, several cases in which the phenotypic expression is strongly affected by the environmental stressors of the individual. The final phenotypic expression seems to be an amalgam of the genotype along with the environmental factors. In 2016. Pinto et al. published a position paper for a revised definition of DCM, introducing a new clinical phenotype and diagnostic criteria for relatives, allowing for better recognition of relatives at risk, while simultaneously emphasizing that DCM may develop after gradual escalation through a continuous spectrum of milder clinical expressions [2].

\section{Epidemiology}

DCM is the commonest indication for heart transplantation and the third most common cause of heart failure [6]. The continuous reclassification and definition amendments of DCM throughout the past decades led to ambiguous data regarding its epidemiology [15]. In 2007, the ESC Working Group on Myocardial and Pericardial Diseases published a position statement that defined cardiomyopathies, segregated them into morphological groups and set diagnostic criteria for each group for both, the probands and their relatives [1]. The prevalence of DCM is estimated to be about 1:2500 in the general population, but this ratio may be an underestimation [16, 17]. Familial DCM has been reported to have a prevalence of $30-50 \%$ of the total DCM cases, while a gene is identified in $20-40 \%$ of those [18-20]. The prevalence seems to be slightly higher in men, with a female to male ratio between 1:1.3 and 1:1.5 [21-23]. DCM has an annual incidence of sudden cardiac death (SCD) between 2 and $4 \%$
[24]. In a registry of survivors of aborted SCD, DCM was found to be the underlying etiology in 10-19\% [25]. SCD may occasionally be the initial manifestation of DCM [24, $26,27]$ including victims with no abnormal autopsy findings [27, 28].

\section{Etiology}

DCM entails a broad group of diseases, acquired or genetic, which result in a similar phenotype. The clinician should always exclude secondary causes before giving the diagnosis of "idiopathic DCM" since some causes may be reversible [29]. The causes of DCM can be classified into genetic and acquired, though the two are not mutually exclusive. Sometimes a genetic predisposition along with the additional effect of environmental factors is what leads to the appearance of the phenotype of the disorder [30, 31].

\section{Acquired DCM}

\section{Drugs and toxins}

Several drugs and toxins, the most common being excess ethanol consumption, cocaine, chloroquine, psychiatric drugs (clozapine, olanzapine), and antineoplastic drugs such as anthracyclines, may directly damage the myocardium causing an acquired form of DCM. Some drugs or toxins can cause acute LV dysfunction, while exposure in toxins such as anthracyclines may lead to LV dysfunction several years after treatment (late-onset cardiotoxicity) [32]. Alcoholic cardiomyopathy accounts for up to $32 \%$ of cases of DCM [33]. Alcohol affects the heart in a dose-dependent manner, while abstinence has the potential for LV systolic dysfunction reversal. On the other hand, anthracycline treatment has typically irreversible cardiotoxic effects [32].

\section{Inflammatory dilated cardiomyopathy}

Myocardial injury caused by infectious agents (viral or bacterial myocarditis), autoimmune disorders (i.e., sarcoidosis), toxic agents (i.e., cocaine), or other factors [34] may trigger an inflammatory response starting with the activation of a proinflammatory cascade of cytokines, followed by an immune response and eventually leading to LV dysfunction and dilatation [35]. Myocarditis progresses to DCM in up to $30 \%$ of cases [34]. Almost half of DMC cases show evidence of inflammation in the myocardium [36].

The entity of autoimmune myocardial inflammation has also been recognized. Patients presenting with infectionnegative myocarditis may progress to DCM [37]. These cases often occur with a familial inheritance pattern. Serum organ-specific anti-heart antibodies may be found 
in symptom-free relatives of DCM patients and are associated with mild LV dysfunction as well as potential progression to DCM [37-39].

\section{COVID-19 and myocardial damage}

Myocardial damage, as indicated by elevated cardiac troponin (cTn) levels and evidence of myocardial edema, and myocardial fibrosis in cardiac magnetic resonance (CMR), are well-recognized cardiac complications of the novel coronavirus, Sars-CoV-2. These abnormalities may occur independently of illness severity, time from the original diagnosis, and preexisting conditions [40]. Elevated $\mathrm{cTn}$ is associated with adverse outcomes and may dictate decisions for hospitalization and further imaging tests in COVID-19 patients [41]. It is suggested that inflammation due to COVID-19 may increase the risk for the development of heart failure with preserved LVEF or DCM. In a case series of 21 COVID-19 patients, $33 \%$ developed cardiomyopathy [42]. Prospective evaluation of COVID-19 patients is required to evaluate this hypothesis.

\section{Peripartum cardiomyopathy}

Peripartum cardiomyopathy (PPCM) is a rare and potentially life-threatening entity in which heart failure develops during the last trimester of pregnancy or in the first few months after delivery [43]. It has been associated with older age, multiparity, presence of hypertension with or without pre-eclampsia, and Afro-Caribbean ethnicity [44]. The conversion of prolactin to an angiostatic factor mediated by oxidative stress is a critical step in the pathogenesis of the disease [45]. Pathogenic variants in genes associated with typical DCM (TTN, MYBPC3) have been detected in cases of PPCM, reinforcing the notion that the combination of genetic predisposition and environmental stressors may decrease the threshold for the expression of the DCM phenotype [44-46].

\section{Combined factors}

All the abovementioned etiologies are not mutually exclusive and may occur in combination [2]. For instance, patients who are carriers of pathogenic variants may also suffer episodes of myocarditis or report excessive ethanol intake, which may sequentially aggravate their overall clinical picture. It is thus required to recognize and remove any environmental risk factors that may worsen the phenotype of someone already at risk of the disease.

\section{Genetic causes of DCM}

\section{Genetic background and inheritance patterns}

Various patterns of inheritance have been recognized, including autosomal dominant, $\mathrm{X}$-linked, autosomal recessive and matrilinear transmission $[1,8,9,16,47,48]$. The genetic yield of DCM is estimated to be about $20-37 \%$ [16, $49,50]$. Until now, more than 50 DCM related genes have been reported [46, 51]. With the development and advances of sequencing technologies, the analysis and discovery of more genes involved in DCM has become feasible, decreasing the frequency of "idiopathic DCM". Studies using nextgeneration sequencing have identified the presence of two or more variants in more than $38 \%$ of affected cases of DCM [52] suggesting a pattern of oligogenic rather than monogenic inheritance in some patients. Of note, there is a considerable overlap of genes involved in the pathogenesis of DCM and other forms of cardiomyopathy, or channelopathies such as Brugada syndrome [2,7]. The presence of more than one pathogenic or likely pathogenic variants in an individual, as well as variants that cause an overlapping cardiomyopathy phenotype, may explain the variable penetration and phenotypic expression, even within the same family.

\section{Most common genes involved in DCM}

A vast array of DCM causative variants have been described so far. These can be classified according to the functional disruption caused at the cellular level. Some of the most studied groups include:

- Sarcomeric DCM - deficit in force generation This group represents the most frequent genetic cause of DCM and consists of genes encoding sarcomeric proteins: titin, myosin, actin, troponin, and tropomyosin. Titin $(T T N)$ is the largest sarcomeric protein within the myocardium. Truncating-TTN variants result in abnormally truncated proteins and are present in $25 \%$ of end-stage disease [30, 53], 20-25\% of familial cases of DCM and in $18 \%$ of sporadic cases, following an autosomal dominant inheritance pattern $[53,54]$. Further research is required to establish whether all truncating TTN variants are pathogenic.

- Nuclear envelope defects (laminopathies) Variants in the Lamin A/C gene (LMNA) are found in up to 6\% of DCM cases [25, 55]. They are inherited in an autosomal dominant pattern and are characterized by an aggressive phenotype with conduction abnormalities and malignant ventricular arrhythmias (VAs). A high incidence of SCD often occurring before the development of significant LV dysfunction [56-58], with a mortality rate of 30\% 
at 12 years of follow-up has been reported [59]. The median age of onset is between 30 and 40 years while the penetrance is almost complete by the age of 70 [59]. The detection of a pathogenic LMNA variant lowers the threshold for an implantable cardioverter defibrillator (ICD) for primary prevention of SCD regardless of the LVEF [60].

- Force transmission deficit (cytoskeletal cardiomyopathy) This group involves genes encoding proteins comprising the cytoskeleton like filamins, dystrophin, and desmin. Pathogenic variants in these genes can lead to muscular dystrophies that are very often associated with DCM. Desmin $(D E S)$ encodes a cytoskeletal protein, a muscle-specific intermediate filament, that helps integrate the sarcolemma, parts of the nuclear membrane, and the Z-disk. Variants in DES may cause a wide phenotypic spectrum of different or overlapping cardiomyopathies, skeletal myopathies, or mixed myopathies (skeletal and cardiac). Cardiac manifestations may be expressed in the form of restrictive cardiomyopathy, DCM, conduction system disorders, Vas, or SCD [61]. Dystrophin (DMD) is located in the $\mathrm{X}$ chromosome, showing an $\mathrm{X}$-linked pattern of inheritance. It has an important role in the formation of a mechanical link between the intracellular cytoskeleton and the extracellular matrix. Heart involvement is found in $90 \%$ and $70 \%$ of the cases of Duchenne's and Becker's muscular dystrophies respectively $[62,63]$. Filamins are large proteins that are responsible for the stabilization of actin filaments and their linkage to the cell membrane. Filamin $\mathrm{C}$ truncation variants are associated with a severe arrhythmogenic DCM phenotype, without the presence of overt skeletal muscle disorder [64].

- Deficits of intercellular adhesion (desmosomal cardiomyopathies) Pathogenic variants in genes encoding desmosomes have been described in both arrhythmogenic right ventricular cardiomyopathy (ARVC) and DCM. Up to $13 \%$ of DCM cases have been associated with desmosomal mutations [65].

Other Variants in the RBM20 gene, involved in the regulation of titin splicing, cause a DCM phenotype with frequent malignant VAs $[7,66]$. BAG3, a gene encoding an antiapoptotic protein has also been implicated in the development of LV dysfunction and DCM phenotype [7, 67].

\section{Diagnosis}

DCM patients often show intermediate phenotypes not fulfilling the standard diagnostic criteria due to variable phenotypic expression and age-dependent penetrance $[68,69]$.
Advanced imaging techniques such as CMR are able to identify subtle or even extensive myocardial scar in patients with normal LV dimensions and function. Significant VAs and SCD may precede any evident structural or morphological changes. Pinto et al. attempted to overcome these limitations, by proposing a revised definition for DCM in 2016 and updating the diagnostic criteria for relatives of DCM patients. Three intermediate categories were proposed: isolated ventricular dilation, arrhythmic cardiomyopathy, and hypokinetic non-dilated cardiomyopathy (HNDC) [2] which filled the gap between no phenotypic expression and fully expressed DCM. HNDC was defined as "left ventricular or biventricular global systolic dysfunction without dilatation (defined as LVEF $<45 \%$ ), not explained by abnormal loading conditions or CAD." Furthermore, the concepts of variable penetrance and gradual progression of the disease from the preclinical to the clinical phase were emphasized, as well as the need for reclassification of the relatives after each followup. A preclinical phase with no or mild cardiac abnormalities such as the expression of anti-heart antibodies or mild LV dilatation was recognized in carriers of DCM-causing variants who were identified through family screening [37-39]. The spectrum of DCM was therefore segregated into different stages, some belonging in the preclinical, early phase with no clear phenotypic expression and others belonging to the clinical phase, as shown in Fig. 1. In 2019, Towbin et al. introduced the term "arrhythmogenic cardiomyopathy" via the HRS expert consensus statement on evaluation, risk stratification, and management of arrhythmogenic cardiomyopathy (ACM). ACM was described as a primary arrhythmogenic disorder of the myocardium incorporating genetic, systemic, infectious, and inflammatory disorders [70]. There is a significant overlap of the ACM phenotype with other cardiomyopathies, particularly DCM and should not be confused with the arrhythmic cardiomyopathy described as the preclinical phase of DCM by Pinto et al.

\section{Diagnostic criteria of DCM in relatives}

Family screening is essential in relatives of patients with DCM or HNDC, as it allows early detection of the disease and early treatment that may help improve prognosis and delay progression $[34,68]$. Pinto et al. described diagnostic criteria in DCM relatives and defined what is considered familial DCM. Major and minor diagnostic criteria were proposed in DCM relatives (see Table 1). According to the findings, relatives are placed into the following 3 categories: definite disease, probable disease, or possible disease. This helps overcome the limitation of having several non-diagnostic abnormalities overlapping with normal phenotypes or may be seen in very common diseases such as hypertension. As the clinical picture is often dynamic, relatives should be recategorized if more criteria are met after each follow-up visit. 
Fig. 1 Clinical spectrum of dilated cardiomyopathy. DCM, dilated cardiomyopathy; HNDC, hypokinetic non-dilated cardiomyopathy; CM, cardiomyopathy; AHA, anti-heart antibodies

\section{Progressive phenotypic \\ expression}

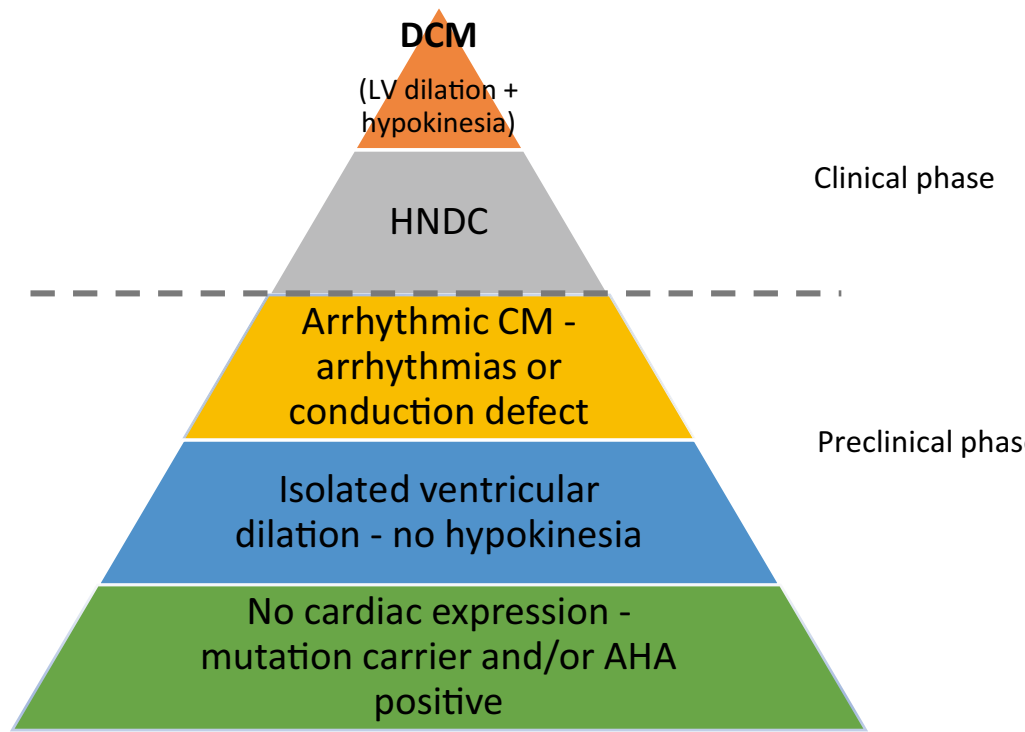

In the absence of a definite pathogenic variant in a family, familial disease is defined as the presence of: (i) 2 or more individuals (first- or second-degree relatives) with definite
DCM or HNDC or (ii) 1 patient fulfilling the diagnostic criteria for DCM or HNDC and a first-degree relative who suffered SCD $<50$ years of age and autopsy-proven DCM [2].
Table 1 Diagnostic criteria for DCM relatives

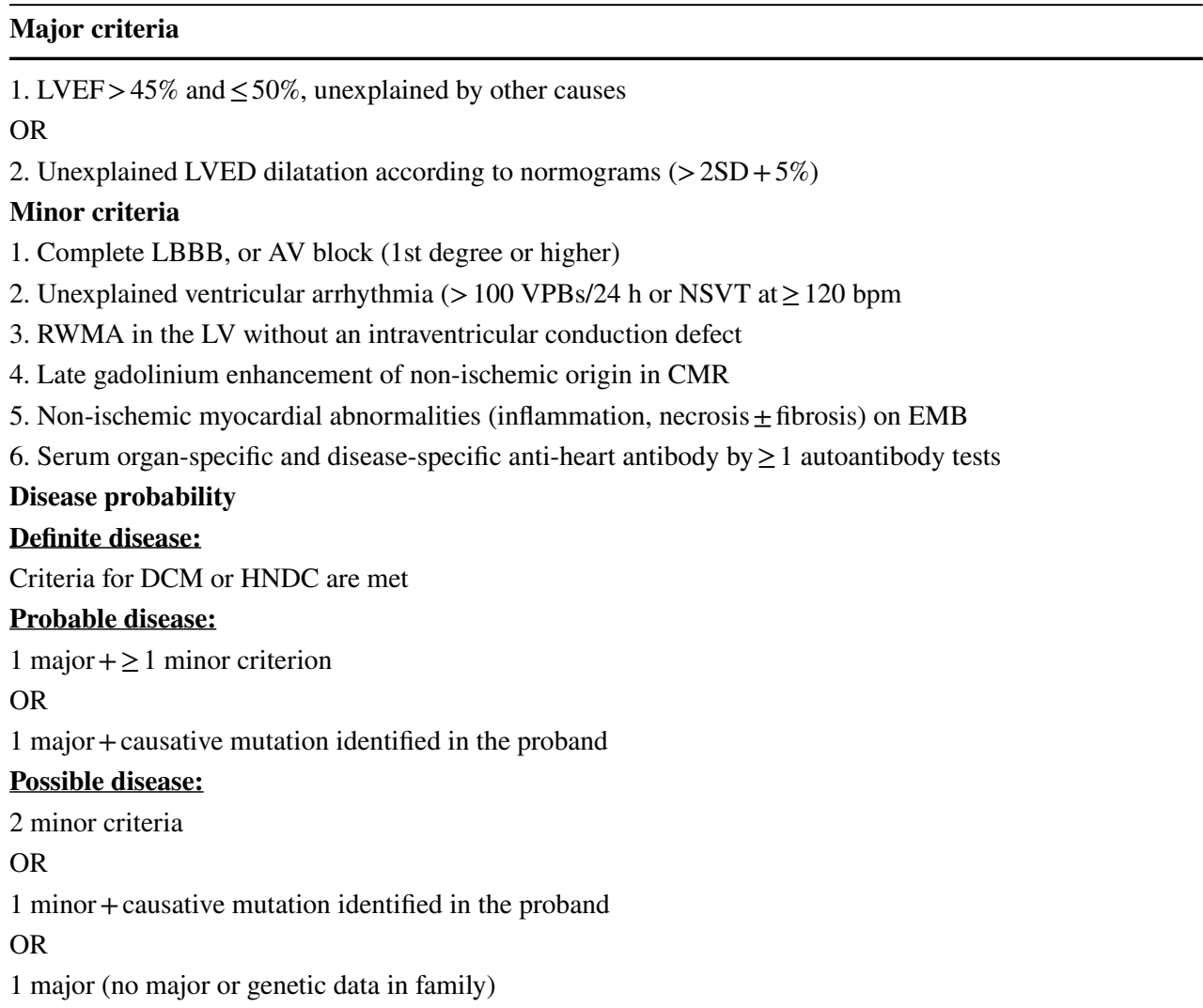

$C M R$ cardiac magnetic resonance, $E M B$ endomyocardial biopsy, $L G E$ late-gadolinium enhancement, $L V E D$ left ventricular end-diastolic, $L V E F$ left ventricular ejection fraction, NSVT non-sustained ventricular tachycardia, $R W M A$ regional wall motion abnormalities, $V P B$ ventricular premature beats 


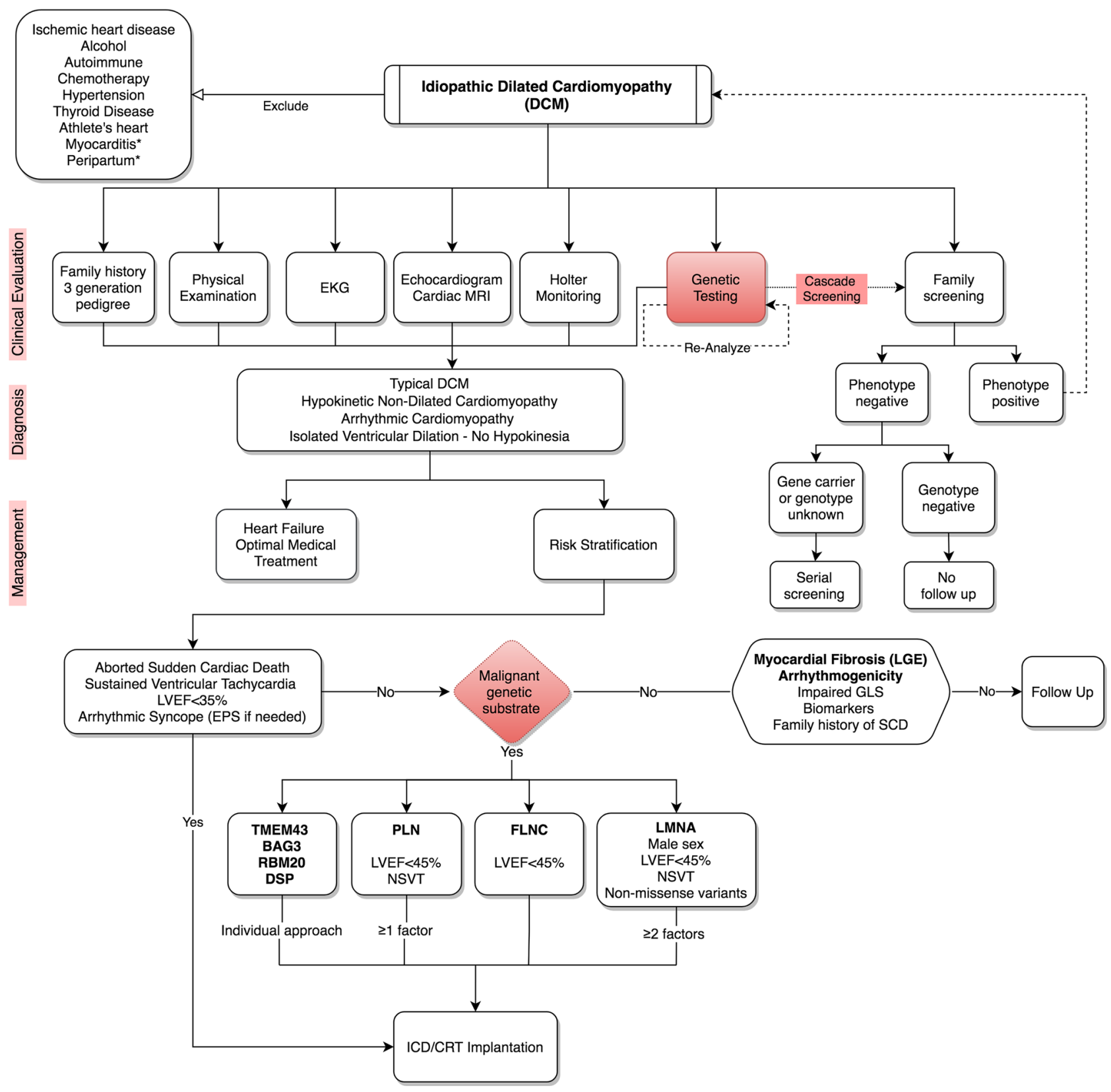

Fig. 2 A clinical management algorithm for DCM. CMR, cardiac magnetic resonance; CRT, cardiac resynchronization therapy; DCM, dilated cardiomyopathy; EPS, electrophysiological study; hs-Tn, highsensitivity troponin; ICD, implanted cardioverted defibrillator; LGE, late gadolinium enhancement; LVEF, left ventricular ejection fraction; NSVT, non-sustained ventricular tachycardia; SCD, sudden cardiac

\section{Diagnostic workup in patients and relatives}

The broad spectrum of disorders leading to DCM mandates a systematic approach to facilitate the identification and management of rarer but specific forms of DCM. It should be emphasized that the diagnostic workup, management, and follow-up of DCM patients are a multifactorial process. Figure 2 death. * A diagnosis of myocarditis or peripartum cardiomyopathy does not exclude the possibility of familial disease. \# Genetic testing should be considered in all cases of DCM, including sporadic cases. An implanted cardioverted defibrillator may be still considered for patients not fulfilling established criteria of high risk of extensive myocardial fibrosis, ventricular arrhythmogenicity, elevated biomarkers

depicts a management algorithm including the indications for ICD implantation according to the genetic substrate of DCM.

Basic evaluation should include personal and family history, physical examination, electrocardiogram (ECG), cardiac imaging and lab testing. The identification of diseasespecific diagnostic clues (red flags) is critical and should guide further diagnostic workup [68]. This may include 
CMR, endomyocardial biopsy (EMB), and genetic testing. If myocarditis is clinically suspected, EMB for detecting infectious agents via histology, immunohistology, and polymerase chain reaction is recommended [2]. When storage or metabolic diseases are suspected and cannot be confirmed otherwise, EMB may also be considered. Secondary etiologies leading to DCM, especially CAD should always be excluded. Exclusion of CAD in patients older than 35 years of age or younger patients with family history of early CAD or with significant CAD risk factors is recommended [2].

Laboratory testing should include hemoglobin and complete blood cell count, liver and kidney function tests, thyroid-stimulating hormone, serum iron, ferritin, calcium, phosphate, natriuretic peptides, Troponin, anti-heart antibodies, and urine analysis for detection of proteinuria [68]. Further testing may be required according to the yield of first-line testing if suspicion of a specific etiology arises.

Dysfunctional hearts are often metabolically deranged. However, the extent to which this might be detectable before the appearance of DCM phenotype is currently unknown. Different biomarkers may be released according to the pathophysiological process, such as strain, myocyte injury, and oxidative stress. The most commonly used biomarkers for heart failure patients are natriuretic peptides, brain natriuretic peptide (BNP) and NT-proBNP that are released during myocardial stretching. Galectin-3 (Gal-3) is an inflammatory component involved in the pathogenetic mechanisms of myocardial fibrosis and has been described as a prognostic marker since the presence of myocardial fibrosis poses a worse prognosis in DCM. The higher the Gal-3 levels the more intense the myocardial fibrosis and LV remodeling [71-73]. Interleukin-33/ST2, belonging to the family of Interleukin-1 (IL-1), is another biomarker reflecting inflammation and myocardial fibrosis [74] that may be used for risk stratification and prognosis in DCM. As a biomarker, it is considered superior to others such as BNP, troponins, and Gal-3 because it is not affected by age, sex, renal function, heart failure history, and body mass index (BMI) [75]. Other more common biomarkers or conditions reflecting a worse prognosis are increased troponins, anemia, and renal failure.

Electrocardiogram (ECG) abnormalities are reported in up to $80 \%$ of patients with DCM [76-78]. A distinct ECG phenotype seems to be related to specific genetic or acquired forms of DCM. Sinus node disease, AV conduction defects, and marked bradycardia are common in LMNA and SCN5A variants. Conduction abnormalities are characteristic of $D M D$ and $D E S$. Low voltage on the ECG, especially in the limb leads, are characteristic of FLNC, PLN, and DSP and may precede any echocardiographic changes. $\mathrm{T}$ wave inversion is found in $F L N C$ and $D S P$. VAs are frequently observed before overt LV dysfunction in LMNA, FLNC, $D E S, D S P$, and $S C N 5 A$ carriers. The combination of conduction abnormalities and complex VAs is highly suggestive of an $L M N A$ variant. A "posterolateral infarction" pattern with pathologic $\mathrm{Q}$ waves (pseudonecrosis) in the inferior and lateral leads should raise suspicion of muscular dystrophy [79].

Specific ECG characteristics have been recognized as prognosticators in DCM. A meta-analysis suggested the potential use of QRS fragmentation and $\mathrm{T}$ wave alternans as prognostic markers for VAs [24]. Atrial fibrillation (AF) has been associated with a worse outcome and need for heart transplantation in DCM [80]. Left bundle branch block (LBBB), present in about a third of patients with DCM, may precede the development of structural changes in the heart and may serve as a poor prognostic indicator [81].

Current criteria for the diagnostic workup of DCM relatives include LBBB, AV block (PR $>200 \mathrm{~ms}$ or higher degree AV block), or unexplained VAs ( $>100$ ventricular premature beats in $24 \mathrm{~h}$ or NSVT at a rate of $>120 \mathrm{bpm}$ [2]. In athletes, LBBB, QRS duration $>140 \mathrm{~ms}$, frequent or complex ventricular arrhythmias, $\mathrm{T}$ wave inversion, and pathological $\mathrm{Q}$ waves are considered pathological and should prompt further investigation [82, 83].

\section{Echocardiography}

Echocardiography is vital in the diagnosis, follow-up, and family screening of DCM. LVEF is a vital parameter and an independent predictor of outcome, since low LVEF values and NYHA functional classes III-IV at baseline have been associated with a higher incidence of death or heart transplantation, in both adults and children [84]. LV dilatation has been described as a predictor of early VAs $[29,85]$. Diffuse LV hypokinesia is usually seen but regional wall motion abnormalities may also be present. It is important to distinguish these from wall motion abnormalities due to $\mathrm{CAD}$, especially if the abnormalities correspond to the anatomic perfusion of a coronary artery. Usually, LV eccentric hypertrophy is present in DCM, along with LV diastolic dysfunction. A restrictive LV filling pattern is independently associated with a poor outcome and heart transplantation [86]. Functional mitral regurgitation, if present, is independently associated with poor prognosis [87]. One of the strongest prognostic indicators in DCM is left ventricular reverse remodeling (LVRR), defined as an LVEF increase of $>10 \%$ or an LVEF $>50 \%$ and a decrease in indexed LVEDD of $>10 \%$ or indexed LVEDD of $>33 \mathrm{~mm} / \mathrm{m}^{2}$ at 24 months [88]. Right ventricular dilatation and dysfunction have prognostic significance and are correlated with a worse functional status and advanced LV failure [89].

Newer echocardiographic techniques, including assessment of myocardial strain and speckle-tracking deformation analysis have been used to detect early phase DCM in relatives with normal LVEF [90]. Global-longitudinal strain is currently being used as a predictor of mortality in 
symptomatic DCM patients but also seems promising in identifying early ventricular dysfunction in asymptomatic variant carriers [90, 91].

\section{Cardiac magnetic resonance}

CMR is very helpful in assessing ventricular size and function along with tissue characterization, especially through the detection of fibrosis via late-gadolinium enhancement (LGE) [34].

In patients with desmoplakin disease who have a normal ECG and VAs of LV origin, the only abnormality detected has been LGE in LV [92]. Sepehrkhouv et al. demonstrated a distinct LGE pattern in patients with pathogenic PLN R14del variants in relation to the pattern seen in other hereditary cardiomyopathies [93]. Both of the aforementioned cardiomyopathies demonstrated fibrosis in the posterolateral wall of the LV, while PLN R14del also showed significantly more fibrosis in the free wall of the LV than the desmosomal variants.

\section{Exercise stress imaging}

Exercise stress imaging has shown some promising results as a potential tool in the diagnosis and prognosis of DCM. The distinction between individuals with DCM and otherwise healthy, athletic individuals is frequently challenging since the two may share an overlapping phenotype due to cardiac remodeling. Millar et al. indicated that an LVEF increase of $>11 \%$ during exercise echocardiography, may distinguish athlete's heart from early DCM [94]. Another study showed the utility of exercise stress CMR in distinguishing asymptomatic patients with suspected DCM from healthy individuals with exercise-induced cardiac remodeling. Patients who had genotype-positive and phenotype-positive DCM had a peak exercise cardiac index below the 35th percentile specific for their age and sex in contrast to healthy individuals [95]. The availability of tools that enable clinicians in distinguishing athlete's heart from DCM is vital for the prevention of SCD since athletes with a clinical diagnosis of DCM should be excluded from most competitive sports [96].

\section{Familial screening}

Familial evaluation is critical in the diagnostic workup of patients with DCM as it allows the identification of relatives with clinical or subclinical DCM in familial cases and provides critical information regarding the phenotypic expression of the condition [26]. Thus, families with an aggressive arrhythmic profile, high ventricular arrhythmia burden, or extensive myocardial fibrosis may be identified. Importantly, a negative family history of DCM does not exclude familial disease, since systematic clinical screening may reveal asymptomatic or subclinical DCM cases [97].

All first-degree relatives should be screened with ECG and echocardiogram. Ambulatory Holter monitoring should be considered if there is evidence of an arrhythmic familial phenotype or symptoms suggestive of arrhythmia. Family screening should begin in childhood and repeated annually through adolescence and every $2-3$ years in adulthood if no abnormalities are detected.

\section{Genetic testing}

According to the latest HRS expert consensus statement on arrhythmogenic cardiomyopathy, genetic testing should be performed in all individuals with a clinical diagnosis of cardiomyopathy or in decedents who were diagnosed with cardiomyopathy at necropsy [70]. The initially selected gene panel and subsequent interpretation should both be based on the phenotype of the patient. Cascade genetic screening and genetic counseling should be offered to first degree relatives if a pathogenic or likely pathogenic variant has been detected in the family [2].

Practice until today suggested that genotype and phenotype negative family members were assured that they carry no risk for developing DCM, and their follow-up was ceased. However, non-monogenic DCM cases have been described [98], and numerous variants that may potentially affect the phenotypic expression are still classified as variants of unknown significance $[99,100]$. At the same time, environmental factors play a vital role in the expression of DCM. It is therefore plausible to say that genotype-negative relatives have a lower risk of developing DCM rather than no risk at all. Continuous surveillance but at more sparse intervals, possibly excluding genes with high penetrance such as $L M N A$, is an alternative strategy for these individuals.

\section{Risk stratification}

For years, risk stratification of DCM patients was based on the degree of LV dysfunction and the presence of symptoms. In symptomatic patients with LVEF $<35 \%$ and a predicted survival of more than 1 year, ICD implantation for primary prevention of SCD is indicated [60,70, 101]. However, a considerable fraction of patients who experience SCD have an LVEF > 35\% [102, 103]. An increasing amount of research supports the utilization of late gadolinium enhancement (LGE) in the risk stratification of DCM patients. LGE is an effective predictor of mortality, hospitalization, and SCD [104, 105]. The presence, extent, and patterns of LGE may also provide predictive data for malignant VAs or LV reverse remodeling $[71,105,106]$. In a meta-analysis by di 
Marco et al., no significant correlation was found between LVEF (above or below 35\%) and malignant VAs [105]. Instead, there was a significant correlation between VAs and the presence and extent of LGE. The correlation between LGE and VAs was maximal in studies that included only patients with primary prevention ICDs.

Due to systematic familial and preparticipation sports screening, DCM patients are commonly detected at an earlier and asymptomatic stage. The risk of heart failure-related events in these patients is low while the risk of life-threatening VAs and SCD may be high. Myocardial fibrosis and specific genetic substrate related to an arrhythmic phenotype have emerged as additional risk stratification markers.

Genotype-phenotype studies have led to the realization that patients with specific genotypes benefit from an ICD for primary prevention even in the absence of severe LV dysfunction. Patients carrying malignant LMNA variants were firstly recognized as a distinct group with a higher SCD risk [101]. In a recent HRS expert consensus document, recommendations for ICD placement in 4 more genes associated with an increased arrhythmic risk in moderately reduced LVEF (BAG3, PLN, FLNC, and TMEM43) were provided [107-111].

More specifically:

- LMNA In a cohort comprising 269 LMNA carriers, the presence of 2 or more of the following risk factors were associated with malignant VAs and SCD: nonsustained ventricular tachycardia (NSVT), LVEF $<45 \%$ at first evaluation, male sex, and non-missense mutations [59]. An ICD implantation is a class IIa indication for $L M N A$ carriers and $\geq 2$ of these risk factors $[60,70$, 101].

- BAG3 Various pathogenic BAG3 variants have been associated with DCM, characterized by high penetrance $>40$ years and a high risk of progressive heart failure (HF) [67] (p. 3), [112-114]. A point mutation in $B A G 3$ gene is already known for causing myofibrillar myopathies with HCM or restrictive cardiomyopathy [67] (p. 3), [110] [113]. There was large phenotypic variability, with 8 out of 18 mutation carriers with DCM undergoing heart transplantation or dying of advanced heart failure, while 3 other carriers showed no penetrance [67]. Risk factors for adverse outcomes in patients with $B A G 3$ pathogenic variants include: male sex, decreased LVEF, and enlarged LVEDD [112].

- PLN A large multicenter cohort study found that carriers of the founder pathogenic R14del PLN variant were at high risk for malignant VAs or end-stage HF. Sustained or NSVT and LVEF $<45 \%$ were independent risk factors for the aforementioned outcomes [111]. High mortality and a poor prognosis were noted from late adolescence. Of note, R14del may cause both, DCM, and ARVC.
Therefore, in patients with phospholamban cardiomyopathy and LVEF $<45 \%$ or NSVT, an ICD should be considered (class IIa indication) [7].

- FLNC Filamin C plays an essential role in the attachment of sarcomeres to the plasmatic membrane. Truncating$F L N C$ variants have been associated with skeletal and cardiac myofibrillar myopathies [115] and an overlapping phenotype of left-dominant arrhythmogenic cardiomyopathy and DCM with high risk of malignant VAs and premature SCD. An autosomal dominant inheritance pattern was indicated with very high penetrance above 40 years old (97\%). The phenotype comprised LV dilation and LV dysfunction, myocardial fibrosis, inferolateral negative $\mathrm{T}$ waves, and low QRS voltages on ECG. VAs were observed in $82 \%$ of the patients with a frequent family history of SCD ( 40 cases in 21 out of 28 families) [64]. Twelve carriers experienced sudden cardiac arrest with a mean LVEF of $39.6 \% \pm 12 \%$ (range 21 to $54 \%$ ). Accordingly, in individuals with FLNC mutation and LVEF $<45 \%$ an ICD is a class IIa indication [7].

- TMEM43 A study in carriers of a transmembrane protein 43 variant (p.S358L-TMEM43) found better survival in those treated with an ICD rather than those under the conventional non-ICD management [110]. Males seem to have a worse prognosis than female carriers since affected males were hospitalized 4 times more often than affected females and died younger [116]. The most frequent $\mathrm{ECG}$ abnormality was poor $\mathrm{R}$ wave progression and was mostly seen in males [110].

- DSP Desmoplakin has been implicated in the development of LV dysfunction and may be involved in DCM and left dominant ARVC [117]. LGE in the LV may be the only abnormality found in patients carrying pathogenic variants of DSP with a normal ECG and arrhythmias of LV origin [92]. The mutation follows an autosomal dominant inheritance pattern.

Non-invasive parameters that have been used in ischemic cardiomyopathy such as premature ventricular complexes, NSVT, late potentials, and prolonged QTc [118] may also be relevant in DCM [119], though further studies are warranted.

\section{Mild DCM in athletes vs. athletic heart syndrome}

Left ventricular dilatation and low-normal left ventricular function (LVEF $<55 \%$ ) occurs in $10-15 \%$ of competitive athletes, especially those engaging in intense endurance training. We demonstrate a practical diagram (Fig. 3) for differentiating between physiological left ventricular enlargement and subclinical DCM in athletes, adapted from Millar et al. [94].The combination of ECG, BNP, $24 \mathrm{~h}$-Holter monitoring, and CMR failed to diagnose more than $30 \%$ of athletic individuals with mild DCM. Exercise 
echocardiography has a much better diagnostic ability. The inability of an individual to increase LVEF by $>11 \%$ or an increase of peak LVEF $>63 \%$ has more than $80 \%$ sensitivity and $90 \%$ specificity for DCM [94].

\section{Genotype dictates sports participation eligibility}

In the 2020 ESC Guidelines on Sports Cardiology, specific recommendations have been described for sports participation in individuals with DCM. In the absence of limiting symptoms or exercise-induced VAs, participation in low to moderateintensity recreational exercise should be considered in all DCM patients regardless of the LVEF [120]. In the presence of $L M N A$ or $F L N C$ genotype, high intensity exercise is prohibited, even in phenotype-negative individuals [120]. In contrast, participation in high- or very high-intensity exercise including competitive sports may be considered in asymptomatic individuals with the following: LVEF $45-50 \%$, no frequent or complex VAs on Holter monitoring or during exercise testing, absence of LGE on CMR, ability to increase LVEF by $10-15 \%$ during exercise, and no high-risk genotype (LMNA or FLNC).

\section{Genetics: the key to the future of DCM}

Genetics have a promising potential to unlock and demystify many of the "blind spots" of the current management of DCM. The rapid expansion and advancements in genetics have come with its own challenges. The interpretation of genetic test results and accurate categorization of variants is a laborious and complicated process and should ideally be performed by multidisciplinary teams of molecular cardiologists, molecular pathologists, clinical geneticists, and genetic counselors.

\section{Genotype-directed treatment}

With the development of genetics, the concept of directing the treatment according to the genotype seems promising [121]. The understanding of gene-specific pathogenetic mechanisms and the unraveling of the functional effects of each variant should dictate different therapeutic strategies. The first attempts towards personalized management of DCM patients based on precision medicine have been made:

- The gain-of-function variant pR222Q in the SCN5A gene is associated with a severe form of arrhythmic DCM [122-124]. Standard heart failure therapies are relatively ineffective in these patients while a dramatic improvement was seen after administration of sodium-channel blocking drugs [123, 125, 126].

- The study of molecular changes involved in LMNAmutated mice revealed increased cardiac activity of the

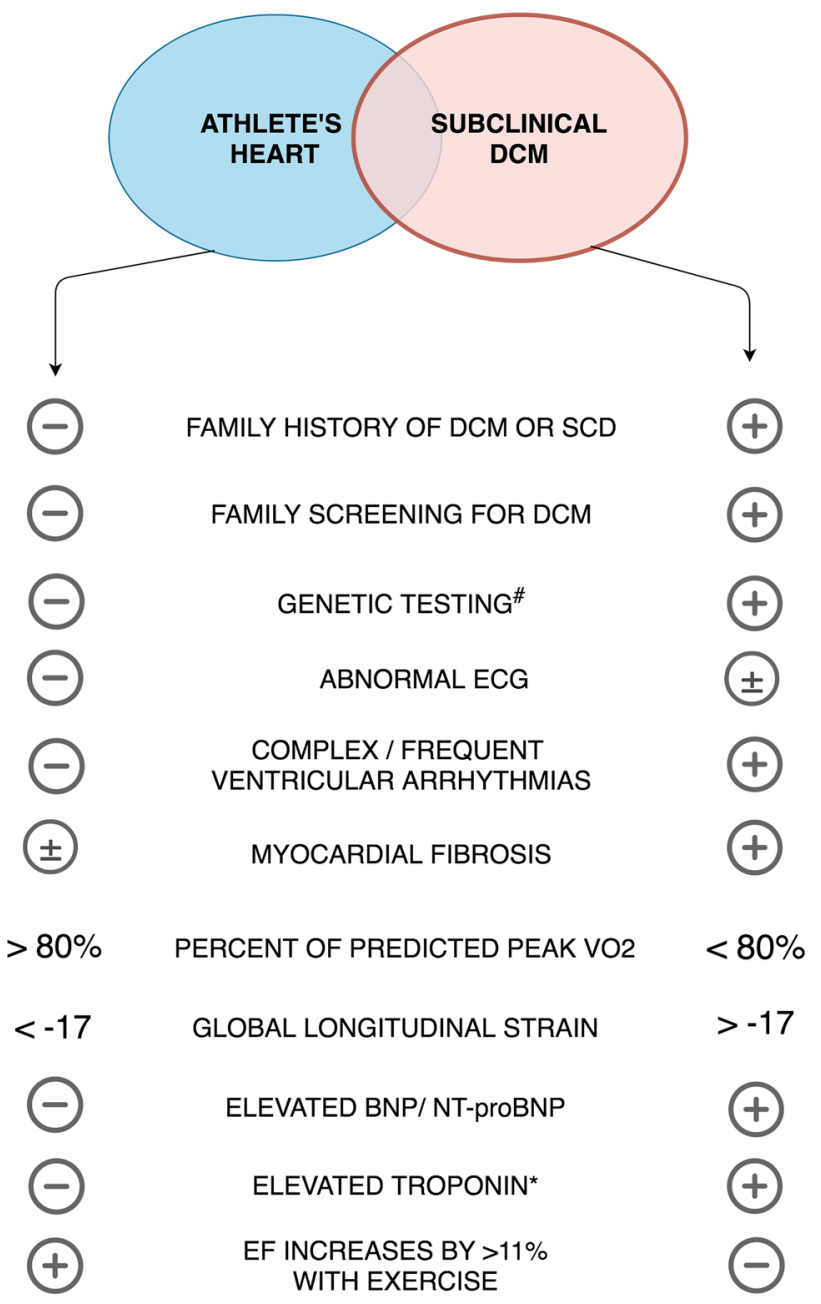

Fig. 3 Diagram for distinguishing between subclinical DCM and athletic heart syndrome. BNP, brain natriuretic peptide; DCM, dilated cardiomyopathy; ECG, electrocardiogram; EF, ejection fraction; NTproBNP, N-terminal pro hormone BNP; SCD, sudden cardiac death; $\mathrm{VO}_{2}$, oxygen consumption. \# For a pathogenic or likely pathogenic variant in a gene associated with dilated cardiomyopathy, * excluding Troponin rise after strenuous exercise

ERK1/2, JNK and p38 MAP kinases. Treatment with a p38 inhibitor in LMNA-mutated mice showed prevention of LV dilation and LV dysfunction [127]. Increasing evidence of beneficial effects of $\mathrm{p} 38$ inhibition led to an international phase 3 clinical trial (NCT03439514), investigating the benefit of ARRY-371797 in symptomatic DCM patients carrying the pathogenic LMNA variant. This randomized, double-blind study is the first genotype-specific treatment study which will hopefully pave the way for other gene-specific treatments.

- Truncating mutations in the TTN gene seem to cause an increase in the cardiac metabolism that eventually leads to sarcomere dysfunction $[128,129]$. Targeting the metabolic alterations caused by TTN mutations could offer a 
potential gene-directed treatment for preventing progression into the DCM phenotype.

- Several gene-editing methods that may directly alter variants are currently under investigation. One such method is the genome-editing tool known as CRISPR/Cas9 which can target specific single-gene mutations such as DMD [130]. An in vivo genome editing study showed restoration of dystrophin expression and cardiac function in dystrophic mice [131].

- Another attractive approach is the utilization of induced pluripotent stem cells (iPSCs) and their subsequent differentiation into cardiomyocytes (iPSCs-CMs). Studies using iPSC-CM modeling have been used in LMNA [132], DES [133], TNNT2 [134, 135], PLN [136], RBM20 [137], TTN [138], and BAG3 [139] variants, with a great fraction of these describing disruption of sarcomeres, decreased contractile force and dysfunctional regulation of calcium. In vivo use of $\beta$-blockers and calcium antagonists showed phenotype attenuation. Two iPSC-CM studies on PLN R14Del used targeted gene correction and lead to full phenotype reversion in vitro $[136,140]$.

Therefore, functional genomics may help in guiding treatment after the identification of the specific function-altering effects of genetic defects. The main challenges in this field are to identify the specific functional change and study any modifier genes or environmental factors that possibly affect the phenotype expression.

\section{Genetic screening and variant classification}

The most important step in genetic testing is the correct identification and interpretation of a pathogenic variant. Not only there is a multitude of variants of unknown significance (VUS), but also already published genes are currently being re-analyzed and re-classified. The ClinGen Cardiovascular Clinical Domain Working Group for cardiovascular disorders is currently in the process of adapting some guidelines of variant interpretation in the genes known to be involved in DCM [141]. Table 2 shows a list of the most up-to-date genes that should be included in the screening of DCM according to the latest position papers and guidelines. In addition, specific ICD indications and genotype-phenotype correlations are included.

\section{Decoding the impact of disease-modifying factors}

The large heterogeneity in phenotype expression of a specific genetic variant is a common clinical conundrum. It highlights the complex genetic architecture of DCM including the presence of multiple variants in the same individual, modifier genes, and the effect of environmental and demographic variables such as age, ethnicity [142], sex, and lifestyle. For example, deleterious $T T N$ variants are more likely to manifest with a DCM phenotype in Europeans than in African-Americans [141]. A multi-parametric score, predicting the likelihood of DCM expression or arrhythmic risk, while considering the genotype and disease-modifying factors of each individual would be an ideal clinical tool but an enormous amount of research is needed before this is achieved and applied in practice.

\section{Prognostic markers and genotype correlation: the importance of long term follow-up}

An important parameter used during follow-up of DCM patients, that reflects improvement and a better prognosis is LVRR.

With adequate pharmacological and device treatment, about $40 \%$ of DCM patients experience significant LVRR [143]. After treatment initiation, the process of LVRR usually needs from 6 months to 2 years to take place [144]. LVRR and the time required to achieve it seem to be strongly related to the long-term prognosis of DCM patients [145]. Some important parameters shown to be affecting the prognosis of the disease and the likelihood of LVRR in the first stages of DCM, should be systematically assessed both at diagnosis and during follow-up. These include right ventricular function [146, 147], functional mitral regurgitation (MR) [148, 149], the presence of LBBB at diagnosis or during follow-up [81, 143].

Recent studies researched the correlation between genotype and the likelihood of LVRR independent of other clinical parameters. Verdonshot et al. suggest an increased likelihood of LVRR with TTN pathogenic variants [150]. In contrast, LMNA mutations seem to be strongly associated with a lower rate of LVRR. Likewise, another study by dal Ferro et al. demonstrated a lack of LVRR with specific genotypes including FLNC, DES, DMD, and other cytoskeletal Z-disk genes, followed by $L M N A$ while again $T T N$ mutations seemed to be associated with higher rates of LVRR under optimal medical treatment [151].

About 15\% of DCM patients show normalization of their LV size and function after sufficient medical treatment. It seems that they maintain an apparently normal cardiac function during a 10-year follow-up. However, in a longer follow-up duration (15 years) $5 \%$ of these patients seem to deteriorate again. Their cardiac function progressively worsens and may die of refractory heart failure, require heart transplantation or ICD implantation $[29,152]$. This is known as the "apparent healing phenomenon". Therefore, even patients that have apparently healed should continue their lifelong follow-up and medical treatment. 
Table 2 Genes to be screened in the workup of DCM - genotype-phenotype correlation and ICD indications [20, 68-70, 154]

\begin{tabular}{|c|c|c|c|}
\hline Gene (protein) & $\begin{array}{l}\text { Frequency in } \\
\text { patients with } \\
\text { DCM }[155]\end{array}$ & Inheritance pattern & Phenotype $[77,156]$ \\
\hline $\boldsymbol{T T N}$ [157] (Titin) & $\begin{array}{l}\text { Truncating } \\
\text { variants } \\
18-25 \% \\
{[30,53,54]}\end{array}$ & $\mathrm{AD}, \mathrm{AR}$ & $\begin{array}{l}\text { Low prevalence of LBBB, atrial fibrillation } \\
\text { Higher frequency of LVRR }[158,159]\end{array}$ \\
\hline ACTC1 [160] (Actin — alpha cardiac 1) & $<1 \%$ & $\mathrm{AD}$ & $\begin{array}{l}\text { p. Gly247Asp variant is associated with atrial } \\
\text { septal defect and late onset DCM [161] } \\
\text { p.(H175R) and p.(Y220H) have been associated } \\
\text { with severe forms of childhood DCM [160] }\end{array}$ \\
\hline LDB3 [162] (LIM domain binding 3) & $<1 \%$ & $\mathrm{AD}$ & Associated with LVNC phenotypes [163] \\
\hline MYBPC3 [164] (Myosin-binding protein C) & $2 \%$ & $\mathrm{AD}$ & $\begin{array}{l}\text { Weak evidence — has been reported in end stage } \\
\text { (burned out phase) HCM } \\
\text { LVNC phenotype }\end{array}$ \\
\hline MYH6 [165] (Myosin heavy chain 6, alpha) & $4 \%$ & $\mathrm{AD}$ & AV conduction defects, sick sinus syndrome \\
\hline MYH7 [166] (Myosin heavy chain 7) & $4 \%$ & $\mathrm{AD}$ & $\begin{array}{l}\text { AV conduction defects may coexist with myopathy } \\
\text { early onset }\end{array}$ \\
\hline $\boldsymbol{T A Z}$ [167] (Tafazzin) & Unknown & X-linked & $\begin{array}{l}\text { DCM with syndromic features: Barth syndrome } \\
\text { (DCM, myopathy, neutropenia, short stature) }\end{array}$ \\
\hline TNNC1 [168] (Troponin C) & $<1 \%$ & $\mathrm{AD}$ & \\
\hline TNNI3 [169] (Troponin I) & $<1 \%$ & $\mathrm{AD}, \mathrm{AR}$ & \\
\hline TNNT2 [166] (Troponin T) & $<1 \%$ & $\mathrm{AD}$ & \\
\hline TPM1 [170] (Tropomyosin 1) & $<1 \%$ & $\mathrm{AD}$ & \\
\hline LMNA [171] (Lamin A/C) & $6 \%[25,27]$ & $A D$ & $\begin{array}{l}\text { Accelerated disease } \\
\text { Atrial fibrillation } \\
\text { VAs often before overt LV dysfunction } \\
\text { AV conduction defects (marked bradycardia/AV } \\
\text { block) }\end{array}$ \\
\hline BAG3 [67] (BCL2-associated anthanogene) & Unknown & $\mathrm{AD}$ & $\begin{array}{l}\text { High penetrance }>40 \text { years } \\
\text { worse prognosis in nonsense variants } \\
\text { Male sex, reduced LVEF and increased LVEDD } \\
\text { associated with a worse prognosis [172] (p. 3) } \\
\text { May coexist with myopathy }\end{array}$ \\
\hline FLNC [173] (Filamin C) & $0-3 \%$ & $\mathrm{AD}$ & $\begin{array}{l}\text { VAs often before overt LV dysfunction } \\
\text { Low QRS voltage } \\
\text { Overlapping phenotype of dilated and left-dominant } \\
\text { arrhythmogenic cardiomyopathies complicated by } \\
\text { frequent premature SCD }\end{array}$ \\
\hline $\boldsymbol{R B M 2 0}$ [66] (RNA binding motif protein 20) & Unknown & $\mathrm{AD}$ & $\begin{array}{l}\text { Malignant VAs } \\
\text { High risk of SCD }\end{array}$ \\
\hline TMEM43 [174] (Transmembrane protein 43) & $<1 \%$ & $\mathrm{AD}$ & $\begin{array}{l}\text { Poor } \mathrm{R} \text { wave progression in precordial leads } \\
\text { Founder variant in Newfoundland } \\
\text { SCD }(\mathrm{M}>\mathrm{F})[174]\end{array}$ \\
\hline PLN [175] (Phospholamban) & $0-12 \%$ & $\mathrm{AD}$ & $\begin{array}{l}\text { Low QRS amplitude, RBBB and loss of inferior } \\
\mathrm{R} \text { waves } \\
\text { Founder mutation in Netherlands } \\
\text { High risk of SCD } \\
\text { Significant posterolateral and free wall fibrosis in } \\
\text { PLN R14del }\end{array}$ \\
\hline DSP [107] (Desmoplakin) & $1-13 \%$ & AD, AR (Carvajal syndrome), & $\begin{array}{l}\text { Low QRS Voltage, VAs } \\
\text { Extensive fibrosis may precede LV systolic } \\
\text { dysfunction and LV dilatation } \\
\text { Episodic myocardial injury } \\
\text { Cardiocutaneous syndrome }\end{array}$ \\
\hline DSG2 [176] (Desmoglein 2) & $4-15$ & $\mathrm{AD}$ & Frequent LV involvement \\
\hline DSC2 [155] (Desmocollin 2) & Unknown & $\mathrm{AD}, \mathrm{AR}$ & \\
\hline
\end{tabular}


Table 2 (continued)

\begin{tabular}{|c|c|c|c|}
\hline Gene (protein) & $\begin{array}{l}\text { Frequency in } \\
\text { patients with } \\
\text { DCM }[155]\end{array}$ & Inheritance pattern & Phenotype $[77,156]$ \\
\hline $\begin{array}{l}S C N 5 A \text { [177] (sodium channel voltage-gated } \\
\text { type V, alpha) }\end{array}$ & $0-2 \%$ & $\mathrm{AD}$ & $\begin{array}{l}\text { Sinus bradycardia, atrial arrhythmias, sinus node } \\
\text { arrest, AV conduction disease } \\
\text { VAs often occur before overt LV dysfunction } \\
\text { May coexist with Brugada Syndrome and/or } \\
\text { Long QT Syndrome type } 3\end{array}$ \\
\hline $\boldsymbol{D E S}$ [178] (Desmin) & $<1 \%$ & $\mathrm{AD}$ & $\begin{array}{l}\text { VAs often before overt LV dysfunction } \\
\text { Skeletal myopathy, conduction disease, RBBB } \\
\text { [179] }\end{array}$ \\
\hline $\boldsymbol{D M D}[62,63]$ (Dystrophin) & Unknown & $\mathrm{X}$-linked & $\begin{array}{l}\text { Inferolateral pseudoinfarction pattern, short PR } \\
\text { interval, RBBB } \\
\text { Duchenne's muscular dystrophy-cardiomyopathy }\end{array}$ \\
\hline $\boldsymbol{E M D}[180]$ (Emerin) & Unknown & X-linked & $\begin{array}{l}\text { Low P-wave amplitude, atrial standstill, atrial } \\
\text { arrhythmias } \\
\text { Emery-Dreifuss muscular dystrophy }\end{array}$ \\
\hline
\end{tabular}

It is recommended that genes primarily associated with HCM and ARVC are also included in the screening [154]

HCM: MYH7, MYBPC3, TNNT2, TNNC1, TNNI3, TPM1, MYL2, MYL3, ACTC1, ACTN2, CSRP3, PLN, TTR, PRKAG2, LAMP2, GLA ARVC: DES, DSC2, DSG2, DSP, JUP, LMNA, PKP2, PLN, RYR2, SCN5A, TMEM43, TTN

$A D$ autosomal dominant, $A R$ autosomal recessive, $A V$ atrioventricular, $A R V C$ arrhythmogenic right ventricular cardiomyopathy, $D C M$ dilated cardiomyopathy, $H C M$ hypertrophic cardiomyopathy, $L B B B$ left-bundle branch block, $L V$ left ventricular, $L V R R$ left ventricular reverse remodeling, $L V N C$ left ventricular non-compaction, $N S V T$ non-sustained ventricular tachycardia, $R B B B$ right bundle branch block, $S C D$ sudden cardiac death, VAs ventricular arrhythmias

\section{Conclusions}

Dilated cardiomyopathy, an "umbrella" term describing the final common phenotype of various etiologies and gene-environment interactions, is now entering a new epoch. We are witnessing the end of the "one-size-fits-all" approach aiming to alleviate symptoms or possibly delay disease progression and the beginning of the precision medicine era. We endorse the concept that we are no longer targeting symptomatic treatment, but instead, we are searching and targeting for the root of the disorder in each individual, with disease prevention or even disease reversal as a goal [153]. We believe that the creation of multi-disciplinary teams in healthcare units may form the core of the individualized management of DCM patients bringing the best patient care possible.

Author contribution All authors contributed in the conception and design of the review. Nicoletta Orphanou drafted the manuscript, Efstathios Papatheodorou, and Aris Anastasakis revised it. All three authors approved the final version of the manuscript and agree to the accuracy and integrity of the work.

Data availability The authors confirm that the data supporting the findings of this study are available within the article (see references).

\section{Declarations}

Conflict of interest The authors declare no competing interests.

\section{References}

1. Elliott P, Andersson B, Arbustini E et al (2007) Classification of the cardiomyopathies: a position statement from the European Society of Cardiology Working Group on Myocardial And Pericardial Diseases. Eur Heart J 29(2):270-276. https://doi.org/10. 1093/eurheartj/ehm342

2. Pinto YM, Elliott PM, Arbustini E et al (2016) Proposal for a revised definition of dilated cardiomyopathy, hypokinetic nondilated cardiomyopathy, and its implications for clinical practice: a position statement of the ESC Working Group on Myocardial and Pericardial Diseases. Eur Heart J 37(23):1850-1858. https:// doi.org/10.1093/eurheartj/ehv727

3. Anastasakis A, Basso C (2018) "Primary" dilated hearts. Int J Cardiol 257:366-370. https://doi.org/10.1016/j.ijcard.2018.01. 002

4. Henry WL, Gardin JM, Ware JH (1980) Echocardiographic measurements in normal subjects from infancy to old age. Circulation 62(5):1054-1061. https://doi.org/10.1161/01.CIR.62.5. 1054

5. Sinagra G, Elliott PM, Merlo M (2020) Dilated cardiomyopathy: so many cardiomyopathies! Eur Heart J 41(39):3784-3786. https://doi.org/10.1093/eurheartj/ehz908

6. Maron BJ, Towbin JA, Thiene $\mathrm{G}$ et al (2006) Contemporary definitions and classification of the cardiomyopathies: an American Heart Association Scientific Statement from the Council on Clinical Cardiology, Heart Failure and Transplantation Committee; Quality of Care and Outcomes Research and Functional Genomics and Translational Biology Interdisciplinary Working Groups; and Council on Epidemiology and Prevention. Circulation 113(14):1807-1816. https://doi.org/10.1161/CIRCULATIONAHA.106.174287

7. Elliott PM, Anastasakis A, Asimaki A et al (2019) Definition and treatment of arrhythmogenic cardiomyopathy: an updated expert 
panel report. Eur J Heart Fail 21(8):955-964. https://doi.org/10. 1002/ejhf.1534

8. Arbustini E, Narula N, Tavazzi L et al (2014) The MOGE(S) classification of cardiomyopathy for clinicians. J Am Coll Cardiol 64(3):304-318. https://doi.org/10.1016/j.jacc.2014.05.027

9. Arbustini E, Morbini P, Pilotto A, Gavazzi A, Tavazzi L (2000) Genetics of idiopathic dilated cardiomyopathy. Herz 25(3):156160. https://doi.org/10.1007/s000590050001

10. Creemers EE, Wilde AA, Pinto YM (2011) Heart failure: advances through genomics. Nat Rev Genet 12(5):357-362. https://doi.org/10.1038/nrg2983

11. Jacoby D, McKenna WJ (2012) Genetics of inherited cardiomyopathy. Eur Heart J 33(3):296-304. https://doi.org/10.1093/eurheartj/ ehr260

12. Pasotti M, Klersy C, Pilotto A et al (2008) Long-term outcome and risk stratification in dilated cardiolaminopathies. J Am Coll Cardiol 52(15):1250-1260. https://doi.org/10.1016/j.jacc.2008.06.044

13. van Berlo JH, de Voogt WG, van der Kooi AJ et al (2005) Metaanalysis of clinical characteristics of 299 carriers of LMNA gene mutations: do lamin $\mathrm{A} / \mathrm{C}$ mutations portend a high risk of sudden death? J Mol Med 83(1):79-83. https://doi.org/10.1007/ s00109-004-0589-1

14. van den Berg MP, van Spaendonck-Zwarts KY, van Veldhuisen DJ, Gietema JA, Postma A, van Tintelen JP (2010) Familial dilated cardiomyopathy: another risk factor for anthracyclineinduced cardiotoxicity? Eur J Heart Fail 12(12):1297-1299. https://doi.org/10.1093/eurjhf/hfq175

15. Rakar S, Sinagra G, Di Lenarda A et al (1997) Epidemiology of dilated cardiomyopathy: a prospective post-mortem study of 5252 necropsies. Eur Heart J 18(1):117-123. https://doi.org/10. 1093/oxfordjournals.eurheartj.a015092

16. Grünig E, Tasman JA, Kücherer H, Franz W, Kübler W, Katus HA (1998) Frequency and phenotypes of familial dilated cardiomyopathy. J Am Coll Cardiol 31(1):186-194. https://doi.org/10. 1016/S0735-1097(97)00434-8

17. Bozkurt B, Colvin M, Cook J et al (2016) Current diagnostic and treatment strategies for specific dilated cardiomyopathies: a scientific statement from the American Heart Association. Circulation 134(23). https://doi.org/10.1161/CIR.0000000000000455

18. Mestroni L, Rocco C, Gregori D et al (1999) Familial dilated cardiomyopathy. J Am Coll Cardiol 34(1):181-190. https://doi. org/10.1016/S0735-1097(99)00172-2

19. Sweet ME, Taylor MR, Mestroni L (2015) Diagnosis, prevalence, and screening of familial dilated cardiomyopathy. Expert Opin Orphan Drugs 3(8):869-876. https://doi.org/10.1517/21678707. 2015.1057498

20. Hershberger RE, Siegfried JD (2011) Update 2011: Clinical and genetic issues in familial dilated cardiomyopathy. J Am Coll Cardiol 57(16):1641-1649. https://doi.org/10.1016/j.jacc.2011.01.015

21. Dolara A, Cecchi F, Ciaccheri M (1989) Cardiomyopathy in Italy today: extent of the problem. G Ital Cardiol 19(11):1074-1079

22. Coughlin SS, Szklo M, Baughman K, Pearson TA (1990) The epidemiology of idiopathic dilated cardiomyopathy in a biracial community. Am J Epidemiol 131(1):48-56. https://doi.org/10. 1093/oxfordjournals.aje.a115484

23. Charron P, Elliott PM, Gimeno JR et al (2018) The Cardiomyopathy Registry of the EURObservational Research Programme of the European Society of Cardiology: baseline data and contemporary management of adult patients with cardiomyopathies. Eur Heart J 39(20):1784-1793. https://doi.org/10.1093/eurheartj/ehx819

24. Goldberger JJ, Subačius H, Patel T, Cunnane R, Kadish AH (2014) Sudden cardiac death risk stratification in patients with nonischemic dilated cardiomyopathy. J Am Coll Cardiol 63(18):1879-1889. https://doi.org/10.1016/j.jacc.2013.12.021

25. van Tintelen JP, Hofstra RMW, Katerberg H et al (2007) High yield of LMNA mutations in patients with dilated cardiomyopathy and/or conduction disease referred to cardiogenetics outpatient clinics. Am Heart J 154(6):1130-1139. https:// doi.org/10.1016/j.ahj.2007.07.038

26. Anastasakis A, Papatheodorou E, Ritsatos K et al (2018) Sudden unexplained death in the young: epidemiology, aetiology and value of the clinically guided genetic screening. EP Eur 20(3):472-480. https://doi.org/10.1093/europace/euw362

27. Lahrouchi N, Raju H, Lodder EM et al (2020) The yield of postmortem genetic testing in sudden death cases with structural findings at autopsy. Eur J Hum Genet 28(1):17-22. https://doi.org/ 10.1038/s41431-019-0500-8

28. Papadakis M, Papatheodorou E, Mellor G et al (2018) The diagnostic yield of Brugada syndrome after sudden death with normal autopsy. J Am Coll Cardiol 71(11):1204-1214. https://doi.org/ 10.1016/j.jacc.2018.01.031

29. Merlo M, Cannatà A, Gobbo M, Stolfo D, Elliott PM, Sinagra G (2018) Evolving concepts in dilated cardiomyopathy: evolving concepts in DCM. Eur J Heart Fail 20(2):228-239. https://doi. org/10.1002/ejhf.1103

30. Roberts AM, Ware JS, Herman DS et al (2015) Integrated allelic, transcriptional, and phenomic dissection of the cardiac effects of titin truncations in health and disease. Sci Transl Med 7(270):270ra6270ra6. https://doi.org/10.1126/scitranslmed.3010134

31. Haggerty CM, Damrauer SM, Levin MG et al (2019) Genomicsfirst evaluation of heart disease associated with titin-truncating variants. Circulation 140(1):42-54. https://doi.org/10.1161/ CIRCULATIONAHA.119.039573

32. Volkova M, Russell R (2012) Anthracycline cardiotoxicity: prevalence, pathogenesis and treatment. Curr Cardiol Rev 7(4):214220. https://doi.org/10.2174/157340311799960645

33. George A, Figueredo VM (2011) Alcoholic cardiomyopathy: a review. J Card Fail 17(10):844-849. https://doi.org/10.1016/j. cardfail.2011.05.008

34. Caforio ALP, Pankuweit S, Arbustini E et al (2013) Current state of knowledge on aetiology, diagnosis, management, and therapy of myocarditis: a position statement of the European Society of Cardiology Working Group on Myocardial and Pericardial Diseases. Eur Heart J 34(33):2636-2648. https://doi.org/10.1093/ eurheartj/eht 210

35. Monda E, Palmiero G, Rubino M et al (2020) Molecular basis of inflammation in the pathogenesis of cardiomyopathies. Int J Mol Sci 21(18):6462. https://doi.org/10.3390/ijms21186462

36. Kühl U, Pauschinger M, Noutsias M et al (2005) High prevalence of viral genomes and multiple viral infections in the myocardium of adults with "idiopathic" left ventricular dysfunction. Circulation 111(7):887-893. https://doi.org/10.1161/01.CIR.0000155616. 07901.35

37. Caforio ALP, Keeling PJ, McKenna WJ et al (1994) Evidence from family studies for autoimmunity in dilated cardiomyopathy. The Lancet 344(8925):773-777. https://doi.org/10.1016/S01406736(94)92339-6

38. Caforio ALP, Mahon NG, Baig MK et al (2007) Prospective familial assessment in dilated cardiomyopathy: cardiac autoantibodies predict disease development in asymptomatic relatives. Circulation 115(1):76-83. https://doi.org/10.1161/CIRCULATIONAHA.106. 641472

39. Mahon NG, Murphy RT, MacRae CA, Caforio ALP, Elliott PM, McKenna WJ (2005) Echocardiographic evaluation in asymptomatic relatives of patients with dilated cardiomyopathy reveals preclinical disease. Ann Intern Med 143(2):108. https://doi.org/ 10.7326/0003-4819-143-2-200507190-00009

40. Puntmann VO, Carerj ML, Wieters I et al (2020) Outcomes of cardiovascular magnetic resonance imaging in patients recently recovered from coronavirus disease 2019 (COVID-19). JAMA Cardiol. Published Online 27 Jul 2020 https://doi.org/10.1001/ jamacardio.2020.3557 
41. Sandoval Y, Januzzi JL, Jaffe AS (2020) Cardiac troponin for assessment of myocardial injury in COVID-19. J Am Coll Cardiol 76(10):1244-1258. https://doi.org/10.1016/j.jacc.2020.06. 068

42. Arentz M, Yim E, Klaff L et al (2020) Characteristics and outcomes of 21 critically ill patients with COVID-19 in Washington State. JAMA 323(16):1612. https://doi.org/10.1001/jama.2020. 4326

43. Sliwa K, Hilfiker-Kleiner D, Petrie MC et al (2010) Current state of knowledge on aetiology, diagnosis, management, and therapy of peripartum cardiomyopathy: a position statement from the Heart Failure Association of the European Society of Cardiology Working Group on peripartum cardiomyopathy. Eur J Heart Fail 12(8):767-778. https://doi.org/10.1093/eurjhf/hfq120

44. Endorsed by the European Society of Gynecology (ESG), the Association for European Paediatric Cardiology (AEPC), and the German Society for Gender Medicine (DGesGM), Authors/Task Force Members, Regitz-Zagrosek V et al (2011) ESC Guidelines on the management of cardiovascular diseases during pregnancy: The Task Force on the Management of Cardiovascular Diseases during Pregnancy of the European Society of Cardiology (ESC). Eur Heart J 32(24):3147-3197. https://doi.org/10.1093/eurheartj/ ehr218

45. Hilfiker-Kleiner D, Haghikia A, Berliner D et al (2017) Bromocriptine for the treatment of peripartum cardiomyopathy: a multicentre randomized study. Eur Heart J 38(35):2671-2679. https://doi.org/10.1093/eurheartj/ehx355

46. van Spaendonck-Zwarts KY, van Rijsingen IAW, van den Berg MP et al (2013) Genetic analysis in 418 index patients with idiopathic dilated cardiomyopathy: overview of 10 years' experience. Eur J Heart Fail 15(6):628-636. https://doi.org/10.1093/ eurjhf/hft013

47. Anastasakis A, Sevdalis E, Papatheodorou E, Stefanadis C (2011) Anderson-Fabry disease: a cardiomyopathy that can be cured. Hell J Cardiol HJC Hell Kardiologike Epitheorese 52(4):316-326

48. Anastasakis A, Papatheodorou E, Steriotis AK (2013) Fabry disease and cardiovascular involvement. Curr Pharm Des 19(33):59976008. https://doi.org/10.2174/13816128113199990353

49. Michels VV, Moll PP, Miller FA et al (1992) The frequency of familial dilated cardiomyopathy in a series of patients with idiopathic dilated cardiomyopathy. N Engl J Med 326(2):77-82. https://doi.org/10.1056/NEJM199201093260201

50. Gigli M, Merlo M, Graw SL et al (2019) Genetic risk of arrhythmic phenotypes in patients with dilated cardiomyopathy. J Am Coll Cardiol 74(11):1480-1490. https://doi.org/10.1016/j.jacc. 2019.06.072

51. Millat G, Bouvagnet $P$, Chevalier P et al (2011) Clinical and mutational spectrum in a cohort of 105 unrelated patients with dilated cardiomyopathy. Eur J Med Genet 54(6):e570-e575. https://doi.org/10.1016/j.ejmg.2011.07.005

52. Haas J, Frese KS, Peil B et al (2015) Atlas of the clinical genetics of human dilated cardiomyopathy. Eur Heart J 36(18):11231135. https://doi.org/10.1093/eurheartj/ehu301

53. Herman DS, Lam L, Taylor MRG et al (2012) Truncations of titin causing dilated cardiomyopathy. N Engl J Med 366(7):619-628. https://doi.org/10.1056/NEJMoa1110186

54. Norton N, Li D, Rampersaud E et al (2013) Exome sequencing and genome-wide linkage analysis in 17 families illustrate the complex contribution of TTN truncating variants to dilated cardiomyopathy. Circ Cardiovasc Genet 6(2):144-153. https://doi. org/10.1161/CIRCGENETICS.111.000062

55. Parks SB, Kushner JD, Nauman D et al (2008) Lamin A/C mutation analysis in a cohort of 324 unrelated patients with idiopathic or familial dilated cardiomyopathy. Am Heart J 156(1):161-169. https://doi.org/10.1016/j.ahj.2008.01.026
56. Taylor MRG, Fain PR, Sinagra G et al (2003) Natural history of dilated cardiomyopathy due to lamin $\mathrm{A} / \mathrm{C}$ gene mutations. J Am Coll Cardiol 41(5):771-780. https://doi.org/10.1016/s07351097(02)02954-6

57. Kumar S, Baldinger SH, Gandjbakhch E et al (2016) Long-term arrhythmic and nonarrhythmic outcomes of lamin A/C mutation carriers. J Am Coll Cardiol 68(21):2299-2307. https://doi.org/ 10.1016/j.jacc.2016.08.058

58. van Rijsingen IAW, Nannenberg EA, Arbustini E et al (2013) Gender-specific differences in major cardiac events and mortality in lamin A/C mutation carriers. Eur J Heart Fail 15(4):376-384. https://doi.org/10.1093/eurjhf/hfs191

59. van Rijsingen IAW, Arbustini E, Elliott PM et al (2012) Risk factors for malignant ventricular arrhythmias in lamin $\mathrm{A} / \mathrm{C}$ mutation carriers. J Am Coll Cardiol 59(5):493-500. https://doi.org/10. 1016/j.jacc.2011.08.078

60. Priori SG, Blomström-Lundqvist C, Mazzanti A et al (2015) 2015 ESC Guidelines for the management of patients with ventricular arrhythmias and the prevention of sudden cardiac death: the task force for the management of patients with Ventricular Arrhythmias and the prevention of sudden cardiac Death of the European Society of Cardiology (ESC). Endorsed by: Association for European Paediatric and Congenital Cardiology (AEPC). Eur Heart J 36(41):2793-2867. https://doi.org/10.1093/eurheartj/ ehv316

61. Hershberger RE, Hedges DJ, Morales A (2013) Dilated cardiomyopathy: the complexity of a diverse genetic architecture. Nat Rev Cardiol 10(9):531-547. https://doi.org/10.1038/nrcardio. 2013.105

62. Politano L, Nigro V, Nigro G et al (1996) Development of cardiomyopathy in female carriers of Duchenne and Becker muscular dystrophies. JAMA 275(17):1335-1338

63. Melacini P, Fanin M, Danieli GA et al (1996) Myocardial involvement is very frequent among patients affected with subclinical Becker's muscular dystrophy. Circulation 94(12):31683175. https://doi.org/10.1161/01.CIR.94.12.3168

64. Ortiz-Genga MF, Cuenca S, Dal Ferro M et al (2016) Truncating FLNC mutations are associated with high-risk dilated and arrhythmogenic cardiomyopathies. J Am Coll Cardiol 68(22):2440-2451. https://doi.org/10.1016/j.jacc.2016.09.927

65. Brun F, Barnes CV, Sinagra G et al (2014) Titin and desmosomal genes in the natural history of arrhythmogenic right ventricular cardiomyopathy. J Med Genet 51(10):669-676. https://doi.org/ 10.1136/jmedgenet-2014-102591

66. Brauch KM, Karst ML, Herron KJ et al (2009) Mutations in ribonucleic acid binding protein gene cause familial dilated cardiomyopathy. J Am Coll Cardiol 54(10):930-941. https://doi.org/ 10.1016/j.jacc.2009.05.038

67. Norton N, Li D, Rieder MJ et al (2011) Genome-wide studies of copy number variation and exome sequencing identify rare variants in BAG3 as a cause of dilated cardiomyopathy. Am J Hum Genet 88(3):273-282. https://doi.org/10.1016/j.ajhg.2011.01.016

68. Rapezzi C, Arbustini E, Caforio ALP et al (2013) Diagnostic work-up in cardiomyopathies: bridging the gap between clinical phenotypes and final diagnosis. A position statement from the ESC Working Group on Myocardial and Pericardial Diseases. Eur Heart J 34(19):1448-1458. https://doi.org/10.1093/eurheartj/ ehs397

69. Charron P, Arad M, Arbustini E et al (2010) Genetic counselling and testing in cardiomyopathies: a position statement of the European Society of Cardiology Working Group on Myocardial and Pericardial Diseases. Eur Heart J 31(22):2715-2726. https:// doi.org/10.1093/eurheartj/ehq271

70. Towbin JA, McKenna WJ, Abrams DJ et al (2019) 2019 HRS expert consensus statement on evaluation, risk stratification, and 
management of arrhythmogenic cardiomyopathy. Heart Rhythm 16(11):e301-e372. https://doi.org/10.1016/j.hrthm.2019.05.007

71. Gulati A, Jabbour A, Ismail TF et al (2013) Association of fibrosis with mortality and sudden cardiac death in patients with nonischemic dilated cardiomyopathy. JAMA 309(9):896. https://doi. org/10.1001/jama.2013.1363

72. Masci PG, Barison A, Aquaro GD et al (2012) Myocardial delayed enhancement in paucisymptomatic nonischemic dilated cardiomyopathy. Int J Cardiol 157(1):43-47. https://doi.org/10. 1016/j.ijcard.2010.11.005

73. Masci PG, Doulaptsis C, Bertella E et al (2014) Incremental prognostic value of myocardial fibrosis in patients with non-ischemic cardiomyopathy without congestive heart failure. Circ Heart Fail 7(3):448-456. https://doi.org/10.1161/CIRCHEARTFAILURE. 113.000996

74. Shah RV, Januzzi JL (2010) ST2: A novel remodeling biomarker in acute and chronic heart failure. Curr Heart Fail Rep 7(1):9-14. https://doi.org/10.1007/s11897-010-0005-9

75. Rehman SU, Mueller T, Januzzi JL (2008) Characteristics of the novel interleukin family biomarker ST2 in patients with acute heart failure. J Am Coll Cardiol 52(18):1458-1465. https://doi. org/10.1016/j.jacc.2008.07.042

76. Momiyama Y, Mitamura H, Kimura M (1994) ECG characteristics of dilated cardiomyopathy. J Electrocardiol 27(4):323-328. https://doi.org/10.1016/S0022-0736(05)80270-5

77. Merlo M, Zaffalon D, Stolfo D et al (2019) ECG in dilated cardiomyopathy: specific findings and long-term prognostic significance. J Cardiovasc Med 20(7):450-458. https://doi.org/10.2459/ JCM.0000000000000804

78. Grimm W, Christ M, Bach J, Müller H-H, Maisch B (2003) Noninvasive arrhythmia risk stratification in idiopathic dilated cardiomyopathy: results of the Marburg Cardiomyopathy Study. Circulation 108(23):2883-2891. https://doi.org/10.1161/01.CIR. 0000100721.52503 .85

79. Finocchiaro G, Papadakis M, Dhutia H et al (2019) Electrocardiographic differentiation between 'benign T-wave inversion' and arrhythmogenic right ventricular cardiomyopathy. EP Eur 21(2):332-338. https://doi.org/10.1093/europace/euy179

80. Aleksova A, Merlo M, Zecchin M et al (2010) Impact of atrial fibrillation on outcome of patients with idiopathic dilated cardiomyopathy: data from the Heart Muscle Disease Registry of Trieste. Clin Med Res 8(3-4):142-149. https://doi.org/10.3121/ cmr.2010.908

81. Aleksova A, Carriere C, Zecchin M et al (2014) New-onset left bundle branch block independently predicts long-term mortality in patients with idiopathic dilated cardiomyopathy: data from the Trieste Heart Muscle Disease Registry. Eur Eur Pacing Arrhythm Card Electrophysiol J Work Groups Card Pacing Arrhythm Card Cell Electrophysiol Eur Soc Cardiol 16(10):1450-1459. https:// doi.org/10.1093/europace/euu016

82. Malhotra A, Dhutia H, Yeo T-J et al (2020) Accuracy of the 2017 international recommendations for clinicians who interpret adolescent athletes' ECGs: a cohort study of 11168 British white and black soccer players. Br J Sports Med 54(12):739-745. https://doi.org/10.1136/bjsports-2017-098528

83. Sharma S, Drezner JA, Baggish A et al (2018) International recommendations for electrocardiographic interpretation in athletes. Eur Heart J 39(16):1466-1480. https://doi.org/10.1093/eurheartj/ ehw631

84. Puggia I, Merlo M, Barbati G et al (2016) Natural history of dilated cardiomyopathy in children. J Am Heart Assoc 5(7). https://doi.org/10.1161/JAHA.116.003450

85. Losurdo P, Stolfo D, Merlo M et al (2016) Early arrhythmic events in idiopathic dilated cardiomyopathy. JACC Clin Electrophysiol 2(5):535-543. https://doi.org/10.1016/j.jacep.2016.05.002
86. Pinamonti B, Di Lenarda A, Sinagra G, Camerini F (1993) Restrictive left ventricular filling pattern in dilated cardiomyopathy assessed by Doppler echocardiography: clinical, echocardiographic and hemodynamic correlations and prognostic implications. J Am Coll Cardiol 22(3):808-815. https://doi.org/ 10.1016/0735-1097(93)90195-7

87. Rossi A, Dini FL, Faggiano P et al (2011) Independent prognostic value of functional mitral regurgitation in patients with heart failure. a quantitative analysis of 1256 patients with ischaemic and non-ischaemic dilated cardiomyopathy. Heart 97(20):1675-1680. https://doi.org/10.1136/hrt.2011.225789

88. Merlo M, Pyxaras SA, Pinamonti B, Barbati G, Di Lenarda A, Sinagra G (2011) Prevalence and prognostic significance of left ventricular reverse remodeling in dilated cardiomyopathy receiving tailored medical treatment. J Am Coll Cardiol 57(13):1468-1476. https://doi.org/10.1016/j.jacc.2010.11.030

89. Puwanant S, Priester TC, Mookadam F, Bruce CJ, Redfield MM, Chandrasekaran K (2009) Right ventricular function in patients with preserved and reduced ejection fraction heart failure. Eur J Echocardiogr 10(6):733-737. https://doi.org/10. 1093/ejechocard/jep052

90. Verdonschot JAJ, Merken JJ, Brunner-La Rocca H-P et al (2020) Value of speckle tracking-based deformation analysis in screening relatives of patients with asymptomatic dilated cardiomyopathy. JACC Cardiovasc Imaging 13(2):549-558. https://doi.org/10.1016/j.jcmg.2019.02.032

91. Romano S, Judd RM, Kim RJ et al (2018) Feature-tracking global longitudinal strain predicts death in a multicenter population of patients with ischemic and nonischemic dilated cardiomyopathy incremental to ejection fraction and late gadolinium enhancement. JACC Cardiovasc Imaging 11(10):14191429. https://doi.org/10.1016/j.jcmg.2017.10.024

92. Norman M, Simpson M, Mogensen J et al (2005) Novel mutation in desmoplakin causes arrhythmogenic left ventricular cardiomyopathy. Circulation 112(5):636-642. https://doi.org/ 10.1161/CIRCULATIONAHA.104.532234

93. Sepehrkhouy S, Gho JMIH, van Es R et al (2017) Distinct fibrosis pattern in desmosomal and phospholamban mutation carriers in hereditary cardiomyopathies. Heart Rhythm 14(7):1024-1032. https://doi.org/10.1016/j.hrthm.2017.03.034

94. Millar LM, Fanton Z, Finocchiaro G et al (2020) Differentiation between athlete's heart and dilated cardiomyopathy in athletic individuals. Heart 106(14):1059-1065. https://doi.org/ 10.1136/heartjnl-2019-316147

95. Le T-T, Bryant JA, Ang BWY et al (2020) The application of exercise stress cardiovascular magnetic resonance in patients with suspected dilated cardiomyopathy. J Cardiovasc Magn Reson 22(1):10. https://doi.org/10.1186/s12968-020-0598-4

96. Pelliccia A, Corrado D, Bjørnstad HH et al (2006) Recommendations for participation in competitive sport and leisuretime physical activity in individuals with cardiomyopathies, myocarditis and pericarditis. Eur J Cardiovasc Prev Rehabil 13(6):876-885. https://doi.org/10.1097/01.hjr.0000238393. 96975.32

97. Hey TM, Rasmussen TB, Madsen T et al (2020) Clinical and genetic investigations of 109 index patients with dilated cardiomyopathy and 445 of their relatives. Circ Heart Fail 13(10). https://doi.org/10.1161/CIRCHEARTFAILURE.119.006701

98. Lee DS, Pencina MJ, Benjamin EJ et al (2006) Association of parental heart failure with risk of heart failure in offspring. N Engl J Med 355(2):138-147. https://doi.org/10.1056/NEJMoa052948

99. Richards S, Aziz N, Bale S et al (2015) Standards and guidelines for the interpretation of sequence variants: a joint consensus recommendation of the American College of Medical Genetics and Genomics and the Association for Molecular Pathology. Genet 
Med Off J Am Coll Med Genet 17(5):405-424. https://doi.org/ 10.1038/gim.2015.30

100. Lahrouchi N, Raju H, Lodder EM et al (2017) Utility of postmortem genetic testing in cases of sudden arrhythmic death syndrome. J Am Coll Cardiol 69(17):2134-2145. https://doi.org/10. 1016/j.jacc.2017.02.046

101. Al-Khatib SM, Stevenson WG, Ackerman MJ et al (2018) 2017 AHA/ACC/HRS guideline for management of patients with ventricular arrhythmias and the prevention of sudden cardiac death: a report of the American College of Cardiology/American Heart Association Task Force on Clinical Practice Guidelines and the Heart Rhythm Society. Circulation 138(13). https://doi.org/10. 1161/CIR.0000000000000549

102. de Vreede-Swagemakers JJM, Gorgels APM, Dubois-Arbouw WI et al (1997) Out-of-hospital cardiac arrest in the 1990s: a population-based study in the Maastricht area on incidence, characteristics and survival. J Am Coll Cardiol 30(6):1500-1505. https://doi.org/10.1016/S0735-1097(97)00355-0

103. Gorgels A (2003) Out-of-hospital cardiac arrest-the relevance of heart failure. The Maastricht Circulatory Arrest Registry. Eur Heart J 24(13):1204-1209. https://doi.org/10.1016/S0195668X(03)00191-X

104. Kuruvilla S, Adenaw N, Katwal AB, Lipinski MJ, Kramer CM, Salerno M (2014) Late gadolinium enhancement on cardiac magnetic resonance predicts adverse cardiovascular outcomes in nonischemic cardiomyopathy: a systematic review and metaanalysis. Circ Cardiovasc Imaging 7(2):250-258. https://doi.org/ 10.1161/CIRCIMAGING.113.001144

105. Di Marco A, Anguera I, Schmitt M et al (2017) Late gadolinium enhancement and the risk for ventricular arrhythmias or sudden death in dilated cardiomyopathy. JACC Heart Fail 5(1):28-38. https://doi.org/10.1016/j.jchf.2016.09.017

106. Masci PG, Schuurman R, Andrea B et al (2013) Myocardial fibrosis as a key determinant of left ventricular remodeling in idiopathic dilated cardiomyopathy: a contrast-enhanced cardiovascular magnetic study. Circ Cardiovasc Imaging 6(5):790-799. https://doi.org/10.1161/CIRCIMAGING.113.000438

107. López-Ayala JM, Gómez-Milanés I, Sánchez Muñoz JJ et al (2014) Desmoplakin truncations and arrhythmogenic left ventricular cardiomyopathy: characterizing a phenotype. EP Eur 16(12):1838-1846. https://doi.org/10.1093/europace/euu128

108. Bhonsale A, Groeneweg JA, James CA et al (2015) Impact of genotype on clinical course in arrhythmogenic right ventricular dysplasia/cardiomyopathy-associated mutation carriers. Eur Heart J 36(14):847-855. https://doi.org/10.1093/eurheartj/ehu509

109. Meune C, Van Berlo JH, Anselme F, Bonne G, Pinto YM, Duboc D (2006) Primary prevention of sudden death in patients with lamin A/C gene mutations. N Engl J Med 354(2):209-210. https://doi.org/10.1056/NEJMc052632

110. Hodgkinson K, Connors S, Merner N et al (2013) The natural history of a genetic subtype of arrhythmogenic right ventricular cardiomyopathy caused by a p.S358L mutation in TMEM43: natural history of a genetic subtype of ARVC. Clin Genet 83(4):321331. https://doi.org/10.1111/j.1399-0004.2012.01919.x

111. van Rijsingen IAW, van der Zwaag PA, Groeneweg JA et al (2014) Outcome in phospholamban R14del carriers: results of a large multicentre cohort study. Circ Cardiovasc Genet 7(4):455465. https://doi.org/10.1161/CIRCGENETICS.113.000374

112. Domínguez F, Cuenca S, Bilińska $Z$ et al (2018) Dilated cardiomyopathy due to BLC2-sssociated athanogene 3 (BAG3) mutations. J Am Coll Cardiol 72(20):2471-2481. https://doi.org/10. 1016/j.jacc.2018.08.2181

113. Odgerel Z, Sarkozy A, Lee H-S et al (2010) Inheritance patterns and phenotypic features of myofibrillar myopathy associated with a BAG3 mutation. Neuromuscul Disord 20(7):438-442. https:// doi.org/10.1016/j.nmd.2010.05.004
114. Selcen D, Muntoni F, Burton BK et al (2008) Mutation in BAG3 causes severe dominant childhood muscular dystrophy. Ann Neurol 65(1):83-89. https://doi.org/10.1002/ana.21553

115. Vorgerd M, van der Ven PFM, Bruchertseifer V et al (2005) A mutation in the dimerization domain of filamin $\mathrm{C}$ causes a novel type of autosomal dominant myofibrillar myopathy. Am J Hum Genet 77(2):297-304. https://doi.org/10.1086/431959

116. Merner ND, Hodgkinson KA, Haywood AFM et al (2008) Arrhythmogenic right ventricular cardiomyopathy type 5 is a fully penetrant, lethal arrhythmic disorder caused by a missense mutation in the TMEM43 gene. Am J Hum Genet 82(4):809821. https://doi.org/10.1016/j.ajhg.2008.01.010

117. Miles C, Finocchiaro G, Papadakis M et al (2019) Sudden death and left ventricular involvement in arrhythmogenic cardiomyopathy. Circulation 139(15):1786-1797. https://doi.org/10.1161/ CIRCULATIONAHA.118.037230

118. Gatzoulis KA, Tsiachris D, Arsenos P et al (2019) Arrhythmic risk stratification in post-myocardial infarction patients with preserved ejection fraction: the PRESERVE EF study. Eur Heart J 40(35):2940-2949. https://doi.org/10.1093/eurheartj/ehz260

119. Gatzoulis KA, Dilaveris P, Arsenos P et al (2020) Arrhythmic risk stratification in nonischemic dilated cardiomyopathy: The ReCONSIDER study design - a two-step, multifactorial, electrophysiology-inclusive approach. Hell J Cardiol HJC Hell Kardiologike Epitheorese. Published Online 21 Apr 2020 https://doi. org/10.1016/j.hjc.2020.03.008

120. Pelliccia A, Sharma S, Gati S et al (2020) 2020 ESC Guidelines on sports cardiology and exercise in patients with cardiovascular disease. Eur Heart J. Published online 29 Aug 2020:ehaa605. https://doi.org/10.1093/eurheartj/ehaa605

121. Bakalakos A, Ritsatos K, Anastasakis A (2018) Current perspectives on the diagnosis and management of dilated cardiomyopathy beyond heart failure: a Cardiomyopathy Clinic Doctor's point of view. Hellenic J Cardiol 59(5):254-261. https://doi.org/ 10.1016/j.hjc.2018.05.008

122. Hershberger RE, Parks SB, Kushner JD et al (2008) Coding sequence mutations identified in MYH7, TNNT2, SCN5A, CSRP3, LBD3, and TCAP from 313 patients with familial or idiopathic dilated cardiomyopathy. Clin Transl Sci 1(1):21-26. https://doi.org/10.1111/j.1752-8062.2008.00017.x

123. Laurent G, Saal S, Amarouch MY et al (2012) Multifocal ectopic Purkinje-related premature contractions. J Am Coll Cardiol 60(2):144-156. https://doi.org/10.1016/j.jacc.2012.02.052

124. McNair WP, Sinagra G, Taylor MRG et al (2011) SCN5A mutations associate with arrhythmic dilated cardiomyopathy and commonly localize to the voltage-sensing mechanism. J Am Coll Cardiol 57(21):2160-2168. https://doi.org/10.1016/j.jacc.2010. 09.084

125. Mann SA, Castro ML, Ohanian M et al (2012) R222Q SCN5A mutation is associated with reversible ventricular ectopy and dilated cardiomyopathy. J Am Coll Cardiol 60(16):1566-1573. https://doi.org/10.1016/j.jacc.2012.05.050

126. Zakrzewska-Koperska J, Franaszczyk M, Bilińska Z et al (2018) Rapid and effective response of the R222Q SCN5A to quinidine treatment in a patient with Purkinje-related ventricular arrhythmia and familial dilated cardiomyopathy: a case report. BMC Med Genet 19(1):94. https://doi.org/10.1186/s12881-018-0599-4

127. Muchir A, Wu W, Choi JC et al (2012) Abnormal p38 mitogen-activated protein kinase signaling in dilated cardiomyopathy caused by lamin A/C gene mutation. Hum Mol Genet 21(19):4325-4333. https://doi.org/10.1093/hmg/dds265

128. Ware JS, Cook SA (2018) Role of titin in cardiomyopathy: from DNA variants to patient stratification. Nat Rev Cardiol 15(4):241-252. https://doi.org/10.1038/nrcardio.2017.190

129. Verdonschot JAJ, Hazebroek MR, Derks KWJ et al (2018) Titin cardiomyopathy leads to altered mitochondrial energetics, 
increased fibrosis and long-term life-threatening arrhythmias. Eur Heart J 39(10):864-873. https://doi.org/10.1093/eurheartj/ehx808

130. Ma N, Zhang JZ, Itzhaki I et al (2018) Determining the pathogenicity of a genomic variant of uncertain significance using CRISPR/Cas9 and human-induced pluripotent stem cells. Circulation 138(23):2666-2681. https://doi.org/10.1161/ CIRCULATIONAHA.117.032273

131. El Refaey M, Xu L, Gao Y et al (2017) In vivo genome editing restores dystrophin expression and cardiac function in dystrophic mice. Circ Res 121(8):923-929. https://doi.org/10.1161/ CIRCRESAHA.117.310996

132. van Mil A, Balk GM, Neef K et al (2018) Modelling inherited cardiac disease using human induced pluripotent stem cellderived cardiomyocytes: progress, pitfalls, and potential. Cardiovasc Res 114(14):1828-1842. https://doi.org/10.1093/cvr/ cvy 208

133. Tse H-F, Ho JCY, Choi S-W et al (2013) Patient-specific inducedpluripotent stem cells-derived cardiomyocytes recapitulate the pathogenic phenotypes of dilated cardiomyopathy due to a novel DES mutation identified by whole exome sequencing. Hum Mol Genet 22(7):1395-1403. https://doi.org/10.1093/hmg/dds556

134. Wu H, Lee J, Vincent LG et al (2015) Epigenetic regulation of phosphodiesterases $2 \mathrm{~A}$ and $3 \mathrm{~A}$ underlies compromised $\beta$-adrenergic signaling in an iPSC model of dilated cardiomyopathy. Cell Stem Cell 17(1):89-100. https://doi.org/10.1016/j. stem.2015.04.020

135. Sun N, Yazawa M, Liu J et al (2012) Patient-specific induced pluripotent stem cells as a model for familial dilated cardiomyopathy. Sci Transl Med 4(130):130ra47. https://doi.org/10.1126/ scitranslmed.3003552

136. Karakikes I, Stillitano F, Nonnenmacher M et al (2015) Correction of human phospholamban R14del mutation associated with cardiomyopathy using targeted nucleases and combination therapy. Nat Commun 6:6955. https://doi.org/10.1038/ncomms7955

137. Wyles SP, Hrstka SC, Reyes S, Terzic A, Olson TM, Nelson TJ (2016) Pharmacological modulation of calcium homeostasis in familial dilated cardiomyopathy: an in vitro analysis from an RBM20 patient-derived iPSC Model. Clin Transl Sci 9(3):158167. https://doi.org/10.1111/cts.12393

138. Hinson JT, Chopra A, Nafissi N et al (2015) Heart Disease. Titin mutations in iPS cells define sarcomere insufficiency as a cause of dilated cardiomyopathy. Science 349(6251):982-986. https:// doi.org/10.1126/science.aaa5458

139. Judge LM, Perez-Bermejo JA, Truong A et al (2017) A BAG3 chaperone complex maintains cardiomyocyte function during proteotoxic stress. JCI Insight 2(14). https://doi.org/10.1172/jci. insight. 94623

140. Stillitano F, Turnbull IC, Karakikes I et al (2016) Genomic correction of familial cardiomyopathy in human engineered cardiac tissues. Eur Heart J 37(43):3282-3284. https://doi.org/10.1093/ eurheartj/ehw307

141. For the ClinGen Cardiovascular Clinical Domain Working Group, Kelly MA, Caleshu C et al (2018) Adaptation and validation of the ACMG/AMP variant classification framework for MYH7-associated inherited cardiomyopathies: recommendations by ClinGen's Inherited Cardiomyopathy Expert Panel. Genet Med 20(3):351-359. https://doi.org/10.1038/gim.2017.218

142. Manrai AK, Funke BH, Rehm HL et al (2016) Genetic misdiagnoses and the potential for health disparities. N Engl J Med 375(7):655-665. https://doi.org/10.1056/NEJMsa1507092

143. Zecchin M, Merlo M, Pivetta A et al (2012) How can optimization of medical treatment avoid unnecessary implantable cardioverterdefibrillator implantations in patients with idiopathic dilated cardiomyopathy presenting with "SCD-HeFT Criteria?" Am J Cardiol 109(5):729-735. https://doi.org/10.1016/j.amjcard.2011.10.033
144. Sinagra G, Merlo M, Pinamonti B (Ed.) (2019) Dilated cardiomyopathy: from genetics to clinical management. Springer International Publishing. https://doi.org/10.1007/978-3-030-13864-6

145. Ruiz-Zamora I, Rodriguez-Capitan J, Guerrero-Molina A et al (2016) Incidence and prognosis implications of long term left ventricular reverse remodeling in patients with dilated cardiomyopathy. Int J Cardiol 203:1114-1121. https://doi.org/10.1016/j. ijcard.2015.11.099

146. Gulati A, Ismail TF, Jabbour A et al (2013) The prevalence and prognostic significance of right ventricular systolic dysfunction in nonischemic dilated cardiomyopathy. Circulation 128(15):16231633. https://doi.org/10.1161/CIRCULATIONAHA.113.002518

147. Merlo M, Gobbo M, Stolfo D et al (2016) The prognostic impact of the evolution of RV function in idiopathic DCM. JACC Cardiovasc Imaging 9(9):1034-1042. https://doi.org/10. 1016/j.jcmg.2016.01.027

148. Stolfo D, Tonet E, Barbati G et al (2015) Acute hemodynamic response to cardiac resynchronization in dilated cardiomyopathy: effect on late mitral regurgitation. Pacing Clin Electrophysiol PACE 38(11):1287-1296. https://doi.org/10.1111/ pace. 12731

149. Stolfo D, Merlo M, Pinamonti B et al (2015) Early improvement of functional mitral regurgitation in patients with idiopathic dilated cardiomyopathy. Am J Cardiol 115(8):1137-1143. https:// doi.org/10.1016/j.amjcard.2015.01.549

150. Verdonschot JAJ, Hazebroek MR, Wang P et al (2018) Clinical phenotype and genotype associations with improvement in left ventricular function in dilated cardiomyopathy. Circ Heart Fail 11(11):e005220. https://doi.org/10.1161/CIRCHEARTFAILURE. 118.005220

151. Dal Ferro M, Stolfo D, Altinier A et al (2017) Association between mutation status and left ventricular reverse remodelling in dilated cardiomyopathy. Heart Br Card Soc 103(21):17041710. https://doi.org/10.1136/heartjnl-2016-311017

152. Merlo M, Stolfo D, Anzini M et al (2015) Persistent recovery of normal left ventricular function and dimension in idiopathic dilated cardiomyopathy during long-term follow-up: does real healing exist? J Am Heart Assoc Cardiovasc Cerebrovasc Dis 4(1). https://doi.org/10.1161/JAHA.114.001504

153. Fatkin D, Huttner IG, Kovacic JC, Seidman JG, Seidman CE (2019) Precision medicine in the management of dilated cardiomyopathy. J Am Coll Cardiol 74(23):2921-2938. https://doi.org/ 10.1016/j.jacc.2019.10.011

154. Hershberger RE, Givertz MM, Ho CY et al (2018) Genetic evaluation of cardiomyopathy - a Heart Failure Society of America Practice Guideline. J Card Fail 24(5):281-302. https://doi.org/ 10.1016/j.cardfail.2018.03.004

155. Gandjbakhch E, Redheuil A, Pousset F, Charron P, Frank R (2018) Clinical diagnosis, imaging, and genetics of arrhythmogenic right ventricular cardiomyopathy/dysplasia. J Am Coll Cardiol 72(7):784-804. https://doi.org/10.1016/j.jacc.2018.05.065

156. Finocchiaro G, Merlo M, Sheikh N et al (2020) The electrocardiogram in the diagnosis and management of patients with dilated cardiomyopathy. Eur J Heart Fail 22(7):1097-1107. https://doi. org/10.1002/ejhf.1815

157. Gerull B, Gramlich M, Atherton J et al (2002) Mutations of TTN, encoding the giant muscle filament titin, cause familial dilated cardiomyopathy. Nat Genet 30(2):201-204. https://doi.org/10. 1038/ng815

158. Akhtar MM, Lorenzini M, Cicerchia M et al (2020) Clinical phenotypes and prognosis of dilated cardiomyopathy caused by truncating variants in the TTN gene. Circ Heart Fail 13(10). https://doi.org/10.1161/CIRCHEARTFAILURE.119.006832

159. Tayal U, Newsome S, Buchan R et al (2017) Truncating variants in titin independently predict early arrhythmias in patients with 
dilated cardiomyopathy. J Am Coll Cardiol 69(19):2466-2468. https://doi.org/10.1016/j.jacc.2017.03.530

160. Vasilescu C, Ojala TH, Brilhante V et al (2018) Genetic basis of severe childhood-onset cardiomyopathies. J Am Coll Cardiol 72(19):2324-2338. https://doi.org/10.1016/j.jacc.2018.08.2171

161. Frank D, Rangrez AY, Friedrich C et al (2019) Cardiac $\alpha$-Actin ( ACTC1 ) gene mutation causes atrial-septal defects associated with late-onset dilated cardiomyopathy. Circ Genomic Precis Med 12(8). https://doi.org/10.1161/CIRCGEN.119.002491

162. Vatta M, Mohapatra B, Jimenez S et al (2003) Mutations in Cypher/ZASP in patients with dilated cardiomyopathy and left ventricular non-compaction. J Am Coll Cardiol 42(11):20142027. https://doi.org/10.1016/j.jacc.2003.10.021

163. Bainbridge MN, Davis EE, Choi W-Y et al (2015) Loss of function mutations in $N N T$ are associated with left ventricular noncompaction. Circ Cardiovasc Genet 8(4):544-552. https:// doi.org/10.1161/CIRCGENETICS.115.001026

164. Daehmlow S, Erdmann J, Knueppel T et al (2002) Novel mutations in sarcomeric protein genes in dilated cardiomyopathy. Biochem Biophys Res Commun 298(1):116-120. https://doi. org/10.1016/s0006-291x(02)02374-4

165. Carroll KJ, Makarewich CA, McAnally J et al (2016) A mouse model for adult cardiac-specific gene deletion with CRISPR/ Cas9. Proc Natl Acad Sci U S A 113(2):338-343. https://doi. org/10.1073/pnas.1523918113

166. Kamisago M, Sharma SD, DePalma SR et al (2000) Mutations in sarcomere protein genes as a cause of dilated cardiomyopathy. N Engl J Med 343(23):1688-1696. https://doi.org/10.1056/ NEJM200012073432304

167. Borkar M, Bijarnia-Mahay S, Kohli S et al (2015) Identification of a novel $T A Z$ gene mutation in a family with $\mathrm{X}$-linked dilated cardiomyopathy Barth syndrome. J Inborn Errors Metab Screen 3:232640981456713. https://doi.org/10.1177/ 2326409814567131

168. Mogensen J, Murphy RT, Shaw T et al (2004) Severe disease expression of cardiac troponin $\mathrm{C}$ and $\mathrm{T}$ mutations in patients with idiopathic dilated cardiomyopathy. J Am Coll Cardiol 44(10):2033-2040. https://doi.org/10.1016/j.jacc.2004.08.027

169. Carballo S, Robinson P, Otway R et al (2009) Identification and functional characterization of cardiac troponin I as a novel disease gene in autosomal dominant dilated cardiomyopathy. Circ Res 105(4):375-382. https://doi.org/10.1161/CIRCRESAHA. 109.196055

170. Olson TM, Kishimoto NY, Whitby FG, Michels VV (2001) Mutations that alter the surface charge of alpha-tropomyosin are associated with dilated cardiomyopathy. J Mol Cell Cardiol 33(4):723-732. https://doi.org/10.1006/jmcc.2000.1339

171. Fatkin D, MacRae C, Sasaki T et al (1999) Missense mutations in the rod domain of the lamin $\mathrm{A} / \mathrm{C}$ gene as causes of dilated cardiomyopathy and conduction-system disease. N Engl J Med 341(23):17151724. https://doi.org/10.1056/NEJM199912023412302

172. Domínguez F, Cuenca S, Bilińska Z et al (2018) Dilated cardiomyopathy due to BLC2-associated athanogene 3 (BAG3) mutations. J Am Coll Cardiol 72(20):2471-2481. https://doi. org/10.1016/j.jacc.2018.08.2181

173. Deo RC, Musso G, Tasan M et al (2014) Prioritizing causal disease genes using unbiased genomic features. Genome Biol 15(12):534. https://doi.org/10.1186/s13059-014-0534-8

174. Milting H, Klauke B, Christensen AH et al (2015) The TMEM43 Newfoundland mutation p.S358L causing ARVC-5 was imported from Europe and increases the stiffness of the cell nucleus. Eur Heart J 36(14):872-881. https://doi.org/10. 1093/eurheartj/ehu077

175. Haghighi K, Kolokathis F, Pater L et al (2003) Human phospholamban null results in lethal dilated cardiomyopathy revealing a critical difference between mouse and human. J Clin Invest 111(6):869-876. https://doi.org/10.1172/JCI17892

176. Garcia-Pavia P, Syrris P, Salas C et al (2011) Desmosomal protein gene mutations in patients with idiopathic dilated cardiomyopathy undergoing cardiac transplantation: a clinicopathological study. Heart Br Card Soc 97(21):1744-1752. https://doi.org/10.1136/hrt.2011.227967

177. Olson TM, Michels VV, Ballew JD et al (2005) Sodium channel mutations and susceptibility to heart failure and atrial fibrillation. JAMA 293(4):447-454. https://doi.org/10.1001/jama.293.4.447

178. Li D, Tapscoft T, Gonzalez O et al (1999) Desmin mutation responsible for idiopathic dilated cardiomyopathy. Circulation 100(5):461-464. https://doi.org/10.1161/01.cir.100.5.461

179. van Tintelen JP, Van Gelder IC, Asimaki A et al (2009) Severe cardiac phenotype with right ventricular predominance in a large cohort of patients with a single missense mutation in the DES gene. Heart Rhythm 6(11):1574-1583. https://doi.org/10.1016/j. hrthm.2009.07.041

180. Ben Yaou R, Gerard M, Chami K et al (2014) G.P.142. Neuromuscul Disord 24(9-10):843-844. https://doi.org/10.1016/j.nmd. 2014.06.172

Publisher's Note Springer Nature remains neutral with regard to jurisdictional claims in published maps and institutional affiliations. 